\title{
Somatodendritic integration under increased network activity in layer 5 pyramidal cells of the somatosensory cortex
}

\author{
Florian B. Neubauer • Thomas Berger
}

Received: 10 July 2007 /Revised: 17 August 2007 / Accepted: 10 September 2007 / Published online: 20 October 2007

(C) Springer-Verlag 2007

\begin{abstract}
Integrative properties of single neurons have been extensively studied in acute brain slices. However, these preparations are characterized by extremely low levels of synaptic and action potential activity. In comparison to in vivo, reduced intracortical input and lack of subcortical modulation increase the effective difference between mean membrane potential and spiking threshold, preventing selfsustained network activity in vitro. To elicit an increased and stable network activity (INA) in vitro comparable to that found in awake animals, we mimicked subcortical cholinergic and serotoninergic inputs using carbachol or barium alone or in combination with serotonin in layer 5 pyramidal cells in slices of mouse somatosensory cortex. INA is primarily induced by a modulation of intrinsic conductances resulting in a depolarization of the membrane potential. We studied the impact of INA on synaptic and somatodendritic integration using extracellular stimulation and dendritic calcium imaging. Synaptic inhibition is strengthened due to an increased driving force for chloride. The critical frequency at which somatic action potentials induce a dendritic calcium action potential is lowered. Simultaneous inhibitory synaptic input is powerful enough to suppress dendritic calcium action potential generation. Pharmacologically induced INA enables the study of neuronal integration in well-accessible cortical slices within an active network.
\end{abstract}

Electronic supplementary material The online version of this article (doi:10.1007/s00424-007-0350-z) contains supplementary material, which is available to authorized users.

F. B. Neubauer · T. Berger $(\bowtie)$ Institute of Physiology, University of Bern, Bühlplatz 5,

3012 Bern, Switzerland

e-mail: berger@pyl.unibe.ch
Keywords Network activation · Neuromodulation . Cholinergic modulation - Serotoninergic modulation . Somatosensory cortex $\cdot$ Dendrite $\cdot$ Patch clamp . Calcium-sensitive dye imaging

\section{Introduction}

Integration in cortical neurons depends on the spatiotemporal distribution of intracortical and subcortical inputs, the leak conductances determining passive membrane properties, and the active conductances generating the output signal of the neuron $[30,46]$. In brain slice preparations, the ability to integrate synaptic input and to generate action potentials is, in general, retained. However, the drive of intracortical ionotropic and subcortical modulatory inputs is dramatically minimized due to the cut of long-range axons innervating the cortex. Together, these changes result in a considerably more hyperpolarized resting membrane potential with low variability in comparison to in vivo recordings [38]. Nevertheless, slice preparations are widely used for the study of functional cellular properties due to an ideal accessibility and visibility. Measurements in awake animals, in contrast, face technical obstacles. There, it is impossible to investigate integrative properties with the same ease, precision, and stability as in vitro. Given this dilemma, a method that establishes integrative properties based on increased network activity (INA) in the slice preparation is highly desirable.

Modulatory input from cholinergic neurons from the brainstem and the basal forebrain is a well-known mechanism for the activation of thalamic and cortical networks, respectively, during the awake state [12, 35, 36, 57]. The depolarizing action of acetylcholine on neocortical neurons is associated with a rise in cell input resistance due to the 
blockade of resting potassium conductances [23, 24]. Serotoninergic input is another strong source of subcortical activation [48].

A well-suited cell type to study integration along the somatodendritc axis is the layer 5 pyramidal cell of the somatosensory cortex. This cell type is characterized by two distinct action potential initiation zones [42]. The somatic initiation zone generates sodium action potentials that backpropagate into the dendrite [50]. The dendritic initiation zone triggers high-threshold calcium action potentials [26]. Both initiation zones interact. Temporal coincidence of a backpropagated somatic action potential and distal dendritic activation is the most likely event to generate a calcium action potential [27]. In contrast, concomitant dendritic GABAergic input is a powerful mechanism to prevent dendritic calcium events (so-called veto effect [27]).

We investigate here the possibility of inducing, in an in vitro preparation, an increased tonic activity level similar to that found in awake animals. Firstly, criteria are defined for such a state, which we name "increased network activity" (INA). Then, three different pharmacological approaches are tested to generate INA in layer 5 pyramidal cells in acute slices of the somatosensory cortex of juvenile mice. Mimicking subcortical input, we were successful in inducing INA. This is mainly based on a depolarization mediated by the modulation of intrinsic conductances. We employ INA to study somatodendritic interaction and the associated veto effect of inhibitory interneurons. Taken together, INA is a promising novel tool to study cortical integration in an acute brain slice preparation under restored network activity.

\section{Material and methods}

Slice preparation Postnatal day 12 to 30 DDY mice were killed by decapitation, following the guidelines of the veterinary office of the canton Bern. Their brains were rapidly removed and immersed in ice-cold artificial cerebrospinal fluid (ACSF). INA was investigated in thalamocortical slices [2] (Figs. 1, 2, 3, 4, 5, 6, and 7) of the somatosensory cortex of P12- to P18-old mice. Dendritic activity was studied in parasagittal slices from P27 to P30 mice (Figs. 8 and 9). Fourhundred-micrometer-thick slices were cut on a vibratome (Microm HM $650 \mathrm{~V}$; Walldorf, Germany), incubated at $35^{\circ} \mathrm{C}$ for $30 \mathrm{~min}$, and afterwards left at room temperature until the transfer to the recording chamber.

Patch-clamp recordings Pyramidal cells in layer 5 of the somatosensory cortex were visualized by infrared differential interference contrast videomicroscopy. Current-clamp whole-cell recordings were obtained from the soma of one or two neurons simultaneously. Two BVC-700A amplifiers were used (Dagan, Minneapolis, MN, USA). Electrodes were made from borosilicate glass tubing with resistances of 4-8 $\mathrm{M} \Omega$ when filled with intracellular solution. All experiments were done at $33^{\circ} \mathrm{C}$. Data were low-pass filtered at $3 \mathrm{kHz}$ using the internal two-pole Bessel filter of the amplifiers and sampled at 5-10 kHz. Capacitance compensation and bridge balance were properly adjusted. Liquid junction potentials were left uncorrected. Only neurons with a mean membrane potential more negative than $-60 \mathrm{mV}$ were recorded [mean membrane potential was $-67.9 \pm 5.6 \mathrm{mV}$, mean \pm standard deviation (SD), $n=54$ cells]. Signals were digitized and stored using Clampex 9 and analyzed off-line with Clampfit 9 (Axon Instruments, Union City, CA, USA). Extracellular stimulation was done using patch pipettes filled with ACSF as monopolar stimulation electrodes.

Electrophysiological data analysis The input resistance was obtained under different pharmacological conditions by a linear fit of the slope of a current-voltage curve. For this curve, a set of steady-state membrane potential values induced by 1-s-long hyperpolarizing current injections was used. The time constant was obtained from a monoexponential fit of the membrane potential decay at the offset of such a hyperpolarizing current pulse. The SD sigma of the membrane potential was obtained in the following way: Shifts in long recordings (up to $10 \mathrm{~min}$ ) of the membrane potential were compensated and a histogram of the resulting trace was fitted with a Gauss function in Clampfit. With this procedure, membrane potential deflections during action potentials did not have an impact on sigma, while changes in excitatory postsynaptic potential (EPSP) and inhibitory postsynaptic potential (IPSP) activity did (see Figs. $1 \mathrm{~b}$ and $2 \mathrm{~b}$ ). Sigma was used for comparison of the variability of the membrane potential under different pharmacological conditions. When parameter changes are presented as percent of control, the control values were obtained from the identical cells prior to pharmacological modulation. Pooled data are expressed as mean \pm SD. Raw data were compared for statistical significance using a paired $t$ test. Significance level was set at $p \leq 0.05$ (* in Table 1), and $p \leq 0.01$ was indicated in Table 1 with **.

Calcium epifluorescence imaging To monitor changes in the intracellular calcium concentration related to dendritic calcium events in layer 5 pyramidal cells ([39]; our Figs. 8 and 9), the potassium salt of the high-affinity calciumsensitive dye Oregon Green 488 BAPTA-1 (OGB-1; Molecular Probes, Eugene, OR, USA) was applied to the cell via the intracellular patch pipette solution. Filling the complete somatodendritic compartment took about 40 $50 \mathrm{~min}$. The light source was a $75 \mathrm{~W}$ Xenon short arc 
lamp in a Deltaram V monochromator (PTI, Lawrenceville, NJ, USA). Changes in epifluorescence were imaged with a Zeiss objective $(40 \times, 0.8$ numerical aperture). A lowresolution $(80 \times 80$ pixel), fast $(500 \mathrm{~Hz}) \mathrm{CCD}$ camera (Redshirt NeuroCCD, RedShirtImaging, Fairfield, CT, USA) running under computer control (Neuroplex software) was used to image changes in fluorescence in a $250 \times$ $250-\mu \mathrm{m}$ field of view covering the distal dendrite around about $625 \mu \mathrm{m}$ from the soma (Figs. 8 and 9). The following filter set for OGB-1 was in use: dichroic mirror $510 \mathrm{~nm}$, emission filter BP540/25 nm. Excitation via the monochromator was at $470 / 6 \mathrm{~nm}$.

Chemicals and solutions Slices were continuously superfused with an ACSF containing (in $\mathrm{mM}$ ): $125 \mathrm{NaCl}, 25$ $\mathrm{NaHCO}_{3}, 2.5 \mathrm{KCl}, 1.25 \mathrm{NaH}_{2} \mathrm{PO}_{4}, 2 \mathrm{CaCl}_{2}, 1 \mathrm{MgCl}_{2}$, and 20 glucose, bubbled with $95 \% \mathrm{O}_{2}$ and $5 \% \mathrm{CO}_{2}$. To induce INA in the slice preparation, we used three different approaches. (a) $\alpha$-Latrotoxin (600-900 pM) and pardaxin $(1-2.7 \mu \mathrm{M})$ were added to the extracellular solution. (b) A modified extracellular solution (mACSF) was used with the following altered concentrations (in $\mathrm{mM}$ ): 5 or $6.25 \mathrm{KCl}$, $1.5 \mathrm{CaCl}_{2}$, and $0.5 \mathrm{MgCl}_{2}$, compared to $2.5,2$, and 1 in ACSF, respectively. (c) The nonhydrolyzable acetylcholine analog carbachol $(20 \mu \mathrm{M})$ or barium $(20-100 \mu \mathrm{M})$ as a blocker of inwardly rectifying potassium currents, as well as serotonin $(10-20 \mu \mathrm{M})$, were added to the extracellular solution. Pipette solution contained (in $\mathrm{mM}$ ): 135 $\mathrm{K}$-gluconate, $5 \mathrm{KCl}, 10$ ethylene glycol bis(2-aminoethyl ether)- $N, N, N^{\prime} N^{\prime}$-tetraacetic acid (EGTA), 10 4-2-hydroxyethyl-1-piperazineethanesulfonic acid (HEPES), $4 \mathrm{Mg}-\mathrm{ATP}$, $0.3 \mathrm{Na}_{2}-\mathrm{GTP}$, and $10 \mathrm{Na}_{2}$ - phosphocreatine, $\mathrm{pH}$ adjusted to 7.25 with $\mathrm{KOH}$. In combined patch-clamp and calcium imaging experiments, the pipette solution contained no EGTA, but in addition $100 \mu \mathrm{M}$ OGB-1. The following antagonists were added to the extracellular solutions: D-2amino-5-phosphonovalerate (D-APV) $50 \mu \mathrm{M}$, and 6-cyano7-nitroquinoxaline-2,3-dione (CNQX) $10 \mu \mathrm{M}$. Pardaxin and $\alpha$-latrotoxin were from Alomone (Jerusalem, Israel) and all other chemicals were from Sigma (St. Louis, MO, USA) or Tocris (Ellisville, MO, USA).

\section{Results}

Definition of increased network activity

For the specification of INA, we rely on parameters obtained in acute brain slice preparations and awake animals. In the literature there is consent that cells in vivo are depolarized in comparison to the in vitro situation and that the amplitude of membrane potential (Vm) fluctuations is much higher $[4,10,11,15,29,33,34,41,49]$ (reviewed in Destexhe et al. [14]). The spiking rate of a neuron is proportional to the probability of the $\mathrm{Vm}$ to cross the spiking threshold. This probabilty in turn depends on two factors, the difference between the mean $\mathrm{Vm}$ and the spiking threshold and the amplitude of actual Vm deflections. As a first criterion for INA, we use the "effective difference" between mean Vm and spiking threshold, which is the controlling variable for the rate of spiking [1]. This effective difference is defined as the absolute difference between mean $\mathrm{Vm}$ and spiking threshold in millivolts divided by the SD of the Gaussian-fitted Vm distribution. We refer to this difference as $T /$ sigma, with $T$ for the difference between mean $\mathrm{Vm}$ and threshold and sigma for the SD [1] (Figs. 1b,c and 2b,c). It expresses the depolarization needed to evoke an action potential as a multiple of the SD of Vm. The smaller the difference between mean $\mathrm{Vm}$ and the spiking threshold and the higher the Vm fluctuations are, the lower $T /$ sigma is and the more likely the generation of action potentials is. In the standard in vitro preparation incubated in ACSF, the value for $T /$ sigma is $71.6 \pm 37.8$ (Table 1), while the values in awake animals were estimated from the literature to be in a range of about 1 to 12 [4, 10, 11, 15, 29, 33, 34, 41, 49]. Our first criterion for INA demands that the $T /$ sigma value obtained for a particular pharmacological condition reaches the range of twice the low $T /$ sigma values found in awake animals, i.e., smaller than 24 . The second criterion is that electrophysiological behavior reached a sustainable steady state. If both criteria are fulfilled, the induced conditions are called INA.

Activation of the presynaptic release machinery using $\alpha$-latrotoxin or pardaxin

In an isolated slice preparation, long-range afferents are cut, and this leads to the hypothesis that lacking synaptic drive is the predominant reason for the increased $T /$ sigma in vitro. Assuming this, a promising technical approach for the induction of INA is the activation of the presynaptic release machinery, while leaving postsynaptic receptors unaffected by the activation protocol itself. Such changes in the synaptic release probability can be obtained with toxins like $\alpha$-latrotoxin [9, 16, 40] and pardaxin [28]. Application of 600 or $900 \mathrm{pM} \alpha$-latrotoxin (concentration range see Capogna et al. [9] and Henze et al. [21]) resulted in a significantly increased SD of the membrane potential distribution (sigma) to $187 \pm 63.8 \%$ of the control value (mean $\pm \mathrm{SD}$ ), reflecting an increased synaptic input to the cells under study ( $p=0.04 ; n=5$ cells; Fig. 1a-c, Table 1$)$. However, the mean membrane potential of the cells was not significantly depolarized ( $p=0.65 ; n=5$ cells; Fig. 1a,c). 
Fig. 1 Effects of $\alpha$-latrotoxin on membrane potential and synaptic transmission. a Bath application of $600 \mathrm{pM}$ $\alpha$-latrotoxin (depicted by the gray line) to a layer 5 pyramidal cell results in increased membrane potential fluctuations and rare action potentials. b Histograms of membrane potential distribution during control and $\alpha$-latrotoxin (black and gray solid curves, respectively) were normalized and fitted with Gauss functions (dotted curves) to obtain the SD sigma. c Analysis of membrane potential recordings under control (black trace, left part) and during $\alpha$-latrotoxin (gray trace, right part). Due to sparse depolarization under $\alpha$-latrotoxin, even increased synaptic drive is not sufficient to bridge the remaining difference $T$ between the mean membrane potential and the spiking threshold. d Activation of synaptic input by extracellular stimulation in layer 2 . Under control conditions, a train of four pulses (400 $\mu$ s duration, 60 or $100 \mu \mathrm{A}$ amplitude, $10 \mathrm{~Hz}$, 30 trials averaged) evokes either EPSPs $(60 \mu \mathrm{A})$ or EPSP-IPSP sequences $(100 \mu \mathrm{A})$ (black traces). With $\alpha$-latrotoxin, synaptic transmission is strengthened, resulting in larger EPSPs and IPSPs in comparison to control $(60 \mu \mathrm{A})$. At stronger stimulation intensity $(100 \mu \mathrm{A})$, strengthened inhibition is masking EPSPs. Mouse P18 a

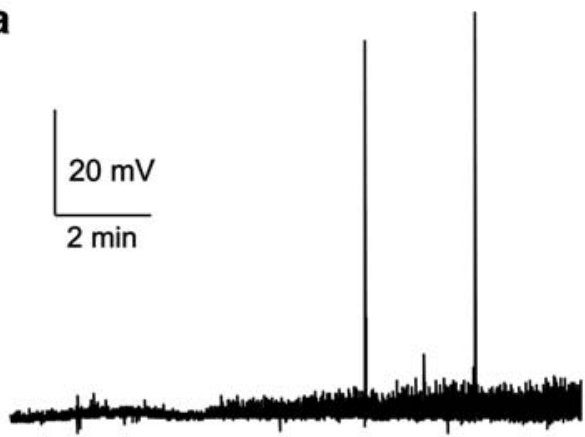

$600 \mathrm{pM} \alpha$-latrotoxin b

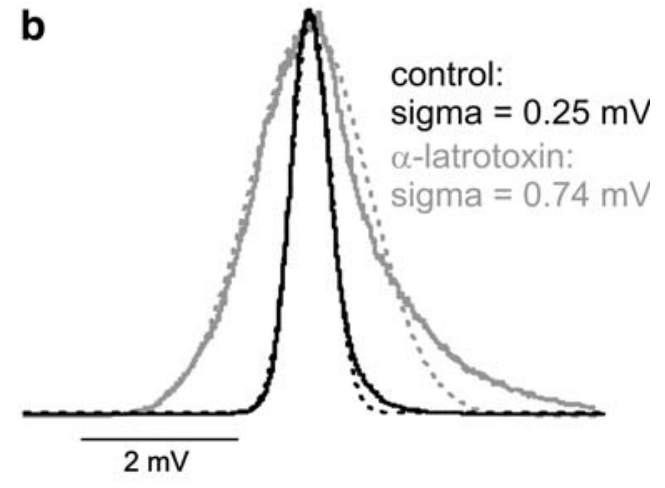

C

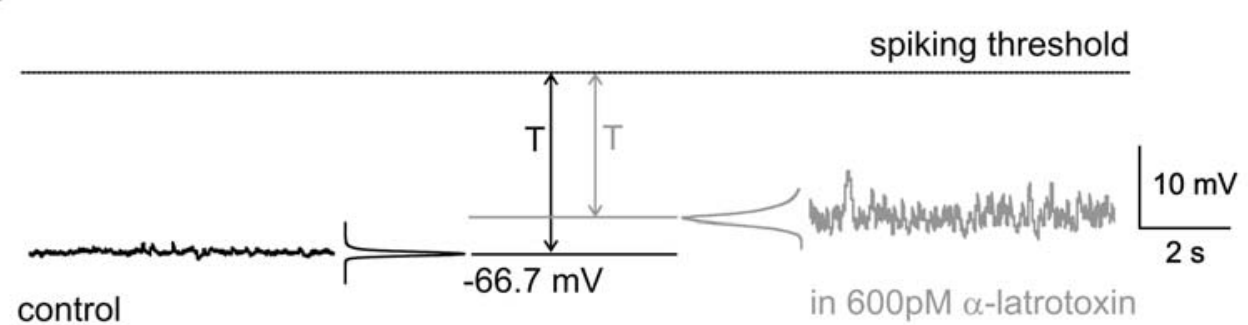

d stimulation intensity $60 \mu \mathrm{A}$ stimulation intensity $100 \mu \mathrm{A}$

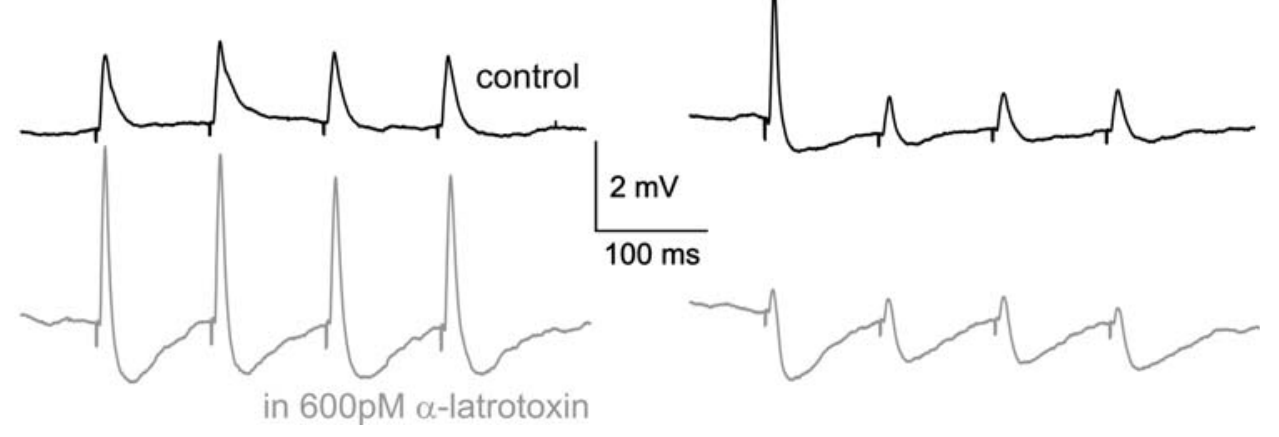

Action potentials occurred only at a very low level (range 0 to $0.12 \mathrm{~Hz}$, median $0 \mathrm{~Hz}$ ). Input resistance and membrane time constant were not significantly changed (Table 1). The obtained values for depolarization and sigma resulted in an effective difference between $\mathrm{Vm}$ and spiking threshold $T /$ sigma of $35.3 \pm 23.6$ ( $p=0.03 ; n=5$ cells; Fig. 1 c), about half the value calculated for the control condition (71.6 \pm $37.8, n=43)$. However, the increase in Vm fluctuations under $\alpha$-latrotoxin was still insufficient to bridge the distance between Vm and spiking threshold as depicted in Fig. 1c.

To check the ability of the system to perform classical synaptic transmission, a patch pipette filled with extracellular solution was placed in layer 2 and used for extracellular stimulation. Four stimuli $(400 \mu$ s duration, 60 or $100 \mu \mathrm{A}$ amplitude, $10 \mathrm{~Hz}$ frequency) evoked 1.5- to 2-mV-large EPSPs in standard ACSF. At higher stimulation intensities, disynaptic IPSPs could be seen (Fig. 1d). Addition of $600 \mathrm{pM} \alpha$-latrotoxin increased the EPSP amplitude at lower stimulation intensities, but these EPSPs were shortened due to a pronounced disynaptic inhibition. Because the membrane potential was only slightly depolarized and the input resistance was unchanged, the increased EPSPs and IPSPs suggest that $\alpha$-latrotoxin improves the synaptic transmission in our preparation. Such an effect may be due to the presynaptic calcium increase following incorporation of $\alpha$-latrotoxin channels in the membrane [20]. With increasing stimulation intensities, inhibition became so prominent that the EPSPs were nearly abolished. This might be explained by the fact that the local circuitry in the cortex is dominated by inhibitory synapses and, at higher stimulation intensities, more and more neighboring interneurons are recruited (Fig. 1d). 

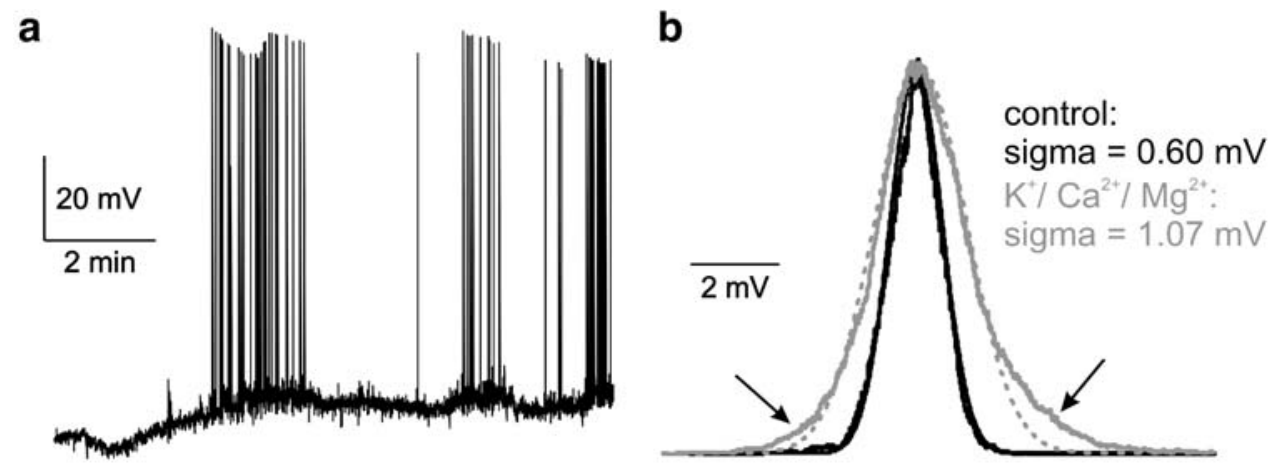

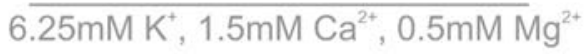

C
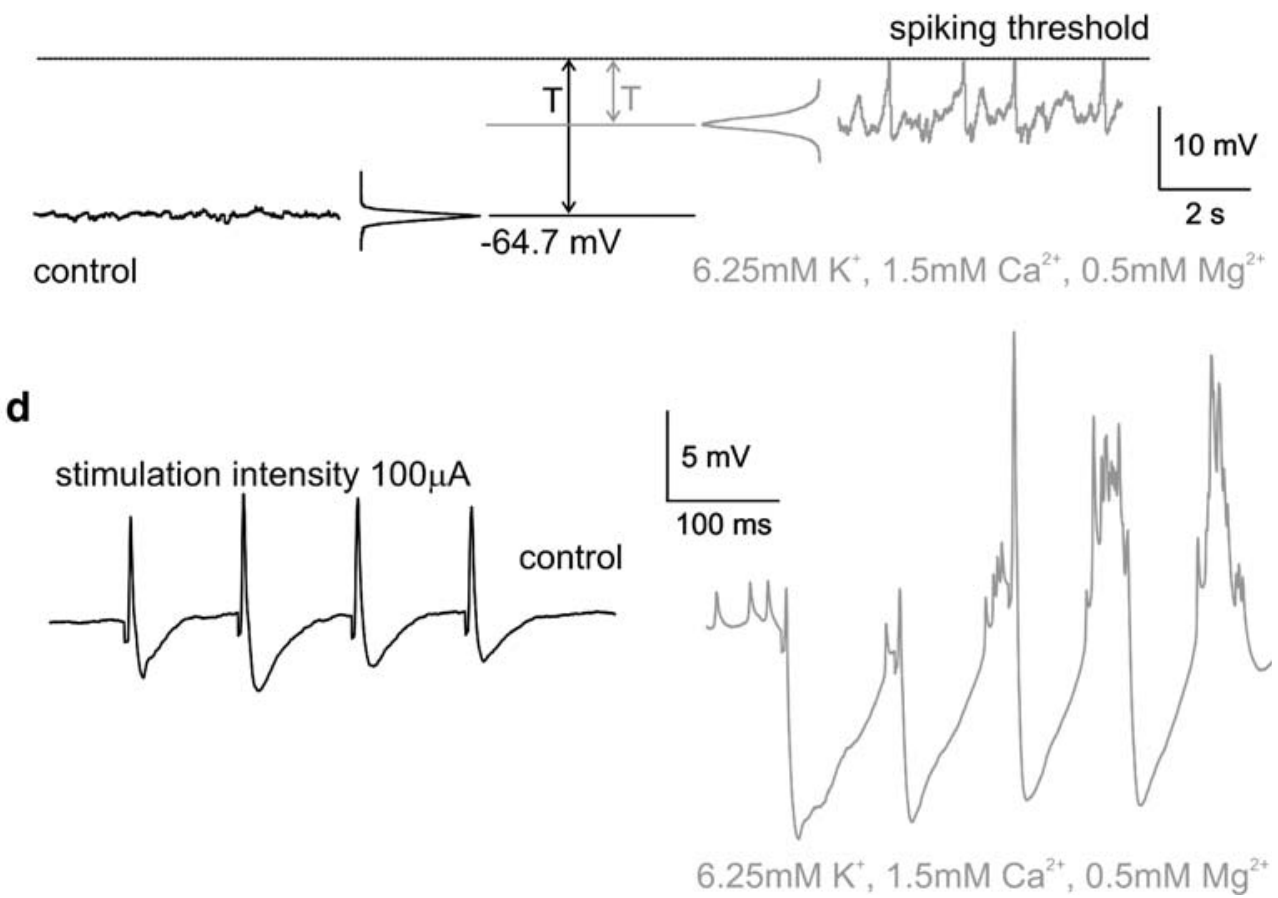

Fig. 2 Effects of increased extracellular potassium and decreased calcium and magnesium concentrations on membrane potential and synaptic transmission. a Extracellular concentrations of $\mathrm{KCl}, \mathrm{CaCl}_{2}$, and $\mathrm{MgCl}_{2}$ were changed to $6.25,1.5$, and $0.5 \mathrm{mM}$ (mACSF), compared to $2.5,2$, and $1 \mathrm{mM}$, respectively, in standard ACSF. The membrane potential of a layer 5 pyramidal cell is shown under control and during mACSF (depicted by the gray line). The cell depolarizes by $17.1 \mathrm{mV}$, sigma increases, and the neuron starts to generate action potentials at a mean frequency of $0.9 \mathrm{~Hz}$. b Histograms of the membrane potential distribution in standard ACSF (control) and mACSF (black and gray solid curves, respectively) were normalized and fitted with Gauss functions (dotted curves) to obtain the sigma

values given. Deflections of the membrane potential from a Gaussiandistributed behavior due to spikes and afterhyperpolarizations (arrows) are neglected by this fitting procedure and do not influence sigma. c Analysis of recording under control (black trace) and under mACSF (gray trace). The differences $T$ between mean $\mathrm{Vm}$ and the spiking threshold reflect sufficient depolarization and synaptic drive under mACSF for the generation of action potentials. Spikes are truncated. d Activation of synaptic input by extracellular stimulation in layer 2 (400 $\mu$ s duration, $100 \mu \mathrm{A}$ amplitude, $10 \mathrm{~Hz}, 30$ trials averaged) under control conditions evokes EPSP-IPSP sequences (black trace). In mACSF, the cell depolarizes, action potentials can be seen, and IPSPs become much larger. Mice P16 (a-c) and P15 (d)

Pardaxin at concentrations of 1 or $2.7 \mu \mathrm{M}$ (concentration range see Henze et al. [21]) resulted in comparable effects. The neurons depolarized slightly but significantly by $3.3 \pm$ $2.4 \mathrm{mV}(p<0.01 ; n=8$ cells $)$. Sigma increased to $141 \pm$ $34.1 \%$ of control $(p<0.01 ; n=8)$. The obtained reduction of $T /$ sigma to $59.7 \pm 45.2$ with pardaxin was not significant
( $p=0.07, n=5$ cells), and there was no spiking. Input resistance and membrane time constant did also not show significant changes under pardaxin (Table 1).

Recordings with $\alpha$-latrotoxin and pardaxin were stable and lasted for $60 \mathrm{~min}$ (median; range 50-120 min), meeting the second criterion for INA, stability in time. However, $T /$ sigma 
Fig. 3 Cholinergic and serotoninergic activation depolarizes the cells and increases the synaptic drive of the network. Application of $50 \mu \mathrm{M}$ barium (a), $20 \mu \mathrm{M}$ serotonin (b), or $10 \mu \mathrm{M}$ serotonin plus $20 \mu \mathrm{M}$ barium (c) all depolarize the cells and lead to action potential generation (left part). An increased sigma reflects the increased synaptic drive under these conditions (right part; here, action potentials are truncated). Membrane potentials: a control: $-66.0 \mathrm{mV}$; $50 \mu \mathrm{M}$ barium: $-59.0 \mathrm{mV}$. b Control: $-65.2 \mathrm{mV}$; $20 \mu \mathrm{M}$ serotonin: $-60.1 \mathrm{mV}$. c Control: $-68.2 \mathrm{mV} ; 10 \mu \mathrm{M}$ serotonin + $20 \mu \mathrm{M}$ barium: $-62.5 \mathrm{mV}$. Mice P14 (a-c)

\section{a}
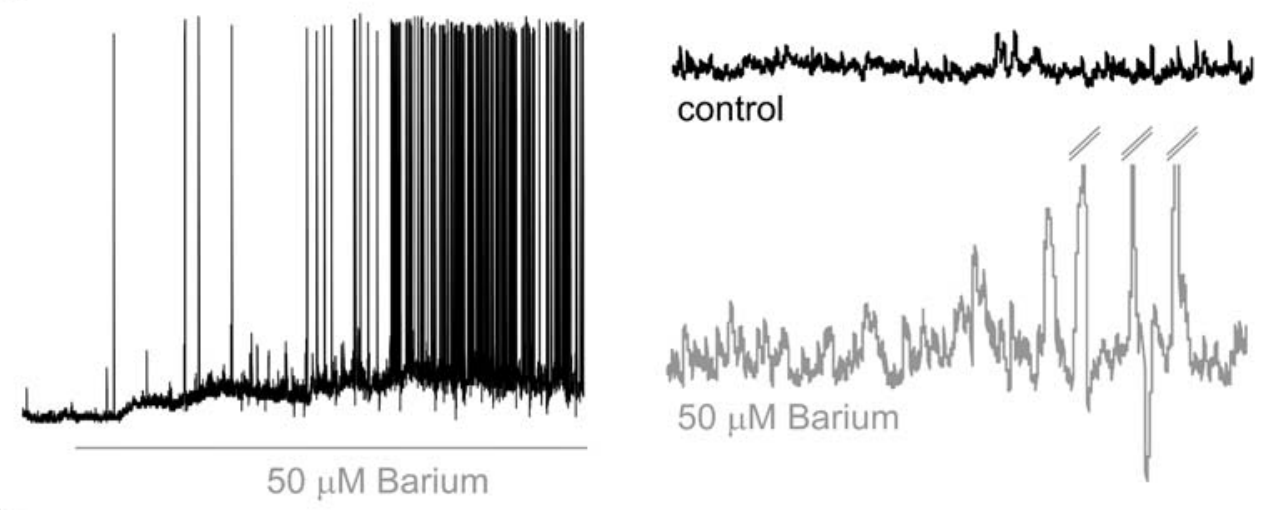

b
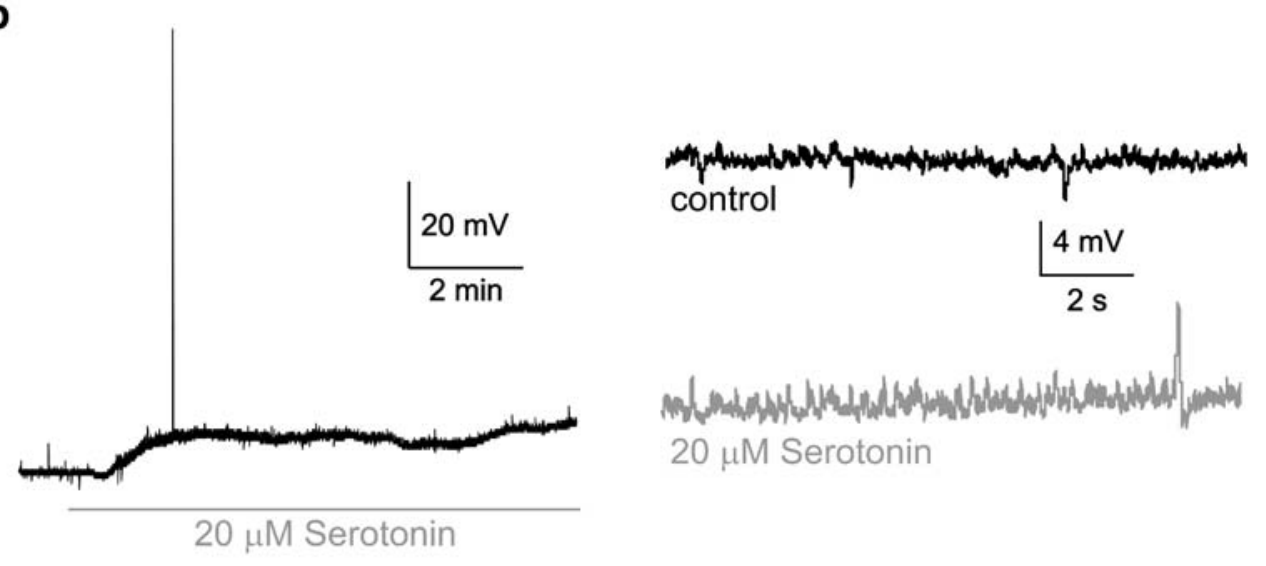

C

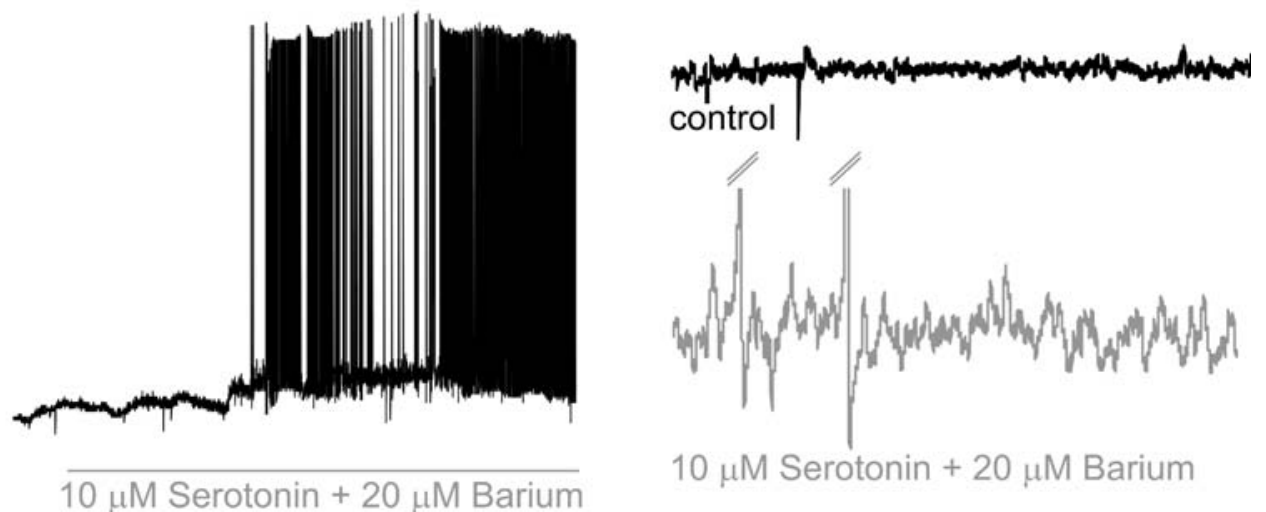

values obtained with exclusive activation of the presynaptic release machinery were far away from the $T /$ sigma value defined in the first criterion (i.e., below 24). Therefore, this pharmacological approach failed to induce INA.

Activation with increased extracellular potassium and decreased calcium and magnesium concentrations

A modified ionic composition of the extracellular medium could be an alternative method to obtain INA. Extracellular potassium concentration was raised to 5 or $6.25 \mathrm{mM}$, while the calcium and magnesium concentrations were lowered to
1.5 and $0.5 \mathrm{mM}$, respectively (mACSF; compare Berger et al. [6] and Silberberg et al. [47]). In contrast to $\alpha$-latrotoxin and pardaxin, mACSF containing $6.25 \mathrm{mM}$ potassium led to a pronounced depolarization of the cells under study by $18.4 \pm 11.1 \mathrm{mV}(p<0.01 ; n=8$ cells $)$. The median of the spiking frequency was $1.15 \mathrm{~Hz}$ (range 0 to $13.0 \mathrm{~Hz} ; n=8$ ). Sigma increased to $256.6 \pm 71.5 \%$ of the control value $(p=0.02 ; n=6$ cells; Fig. $2 \mathrm{~b}, \mathrm{c})$. This increase was not due to the presence of action potentials because sigma values were obtained from Gaussian-fitted histograms rejecting action potentials (Fig. 2b). In comparison to $\alpha$-latrotoxin, the spiking threshold was reached in mACSF primarily due to a 


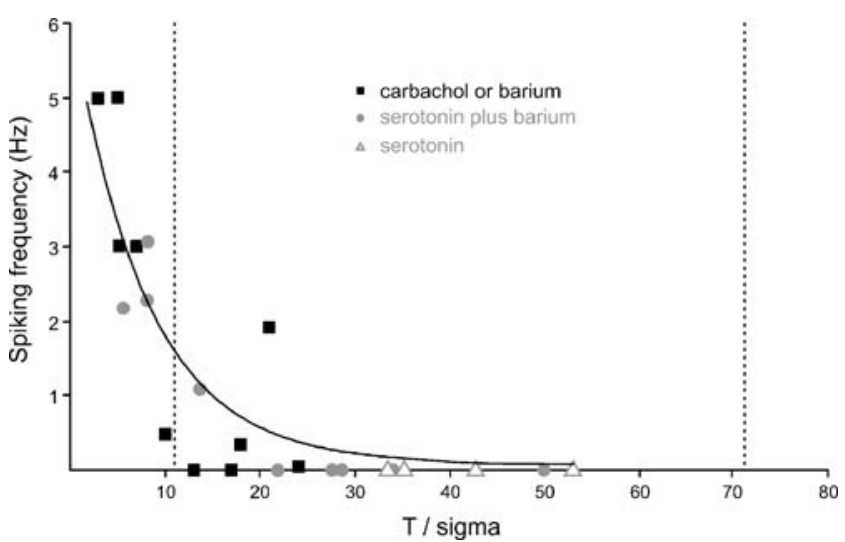

Fig. 4 INA is characterized by the reduction of the effective difference between mean membrane potential and spiking threshold. Plot of the spiking frequency against the effective difference between mean membrane potential and spiking threshold ( $T /$ sigma). Data from 23 cells under INA were fitted logarithmically (black line). Mimicking subcortical input with cholinergic or mixed cholinergic-serotoninergic activation induces INA with low $T /$ sigma values in comparison to the mean control value of 71.6 (right dashed line). Under INA, the $T /$ sigma values are similar to those found in the awake animal, and the highest spiking frequency is $5 \mathrm{~Hz}$. The left dashed line depicts the highest $T /$ sigma values described in awake animals strong depolarization and a concomitant high sigma (Fig. 2c). T/sigma was reduced to $15.8 \pm 8.7$ ( $p<0.01 ; n=$ 6 ), reaching a similar range as observed in vivo. Input resistance and membrane time constant were significantly decreased in mACSF (Table 1). mACSF with $5 \mathrm{mM}$ potassium instead of $6.25 \mathrm{mM}$ had similar but weaker effects (Table 1).

Extracellular stimulation induced EPSPs (not shown) and, at higher stimulation intensities, sequences of EPSPs with disynaptic IPSPs (Fig. 2d). In mACSF, the EPSP component became smaller while the IPSP component increased in amplitude. This may be simply explained by the fact that the cell's membrane potential approached the reversal potential for the cationic AMPA receptors while the driving force for GABAergic conductances increased.

The critical disadvantage of mACSF was the short duration and insufficient stability of the emerging activity (with 5 and $6.25 \mathrm{mM}$ potassium). Neurons often continued to depolarize without reaching a new stable steady-state activity level. After a relatively short time (median $30 \mathrm{~min}$; range $20-100 \mathrm{~min} ; n=20$ cells), they were inactivated by a

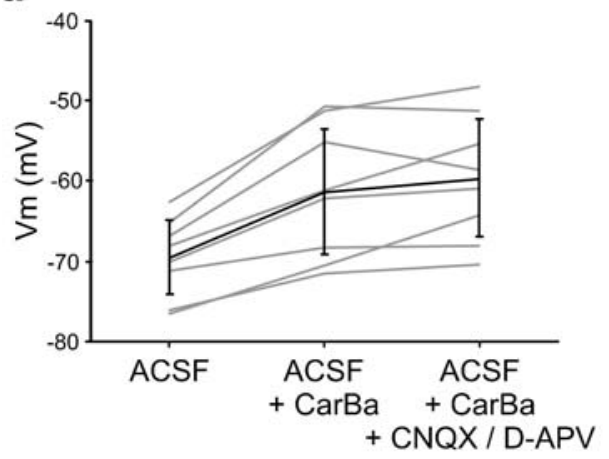

C

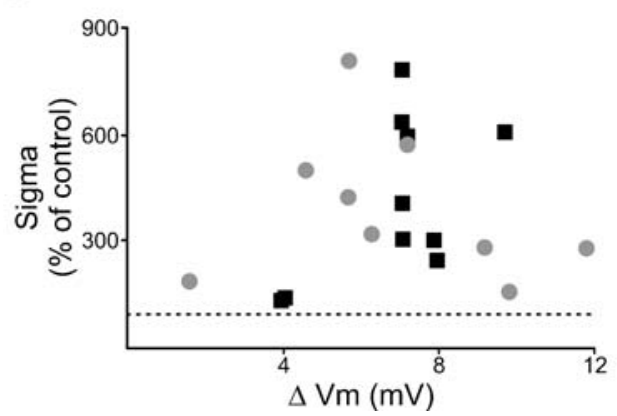

Fig. 5 Depolarization during INA is due to modulation of intrinsic conductances and not due to excitatory synaptic drive in the network. a The membrane potential of eight cells in ACSF, ACSF plus $20 \mu \mathrm{M}$ carbachol or $50 \mu \mathrm{M}$ barium (ACSF $+\mathrm{CarBa}$, cholinergic activation), and ACSF + CarBa plus $10 \mu \mathrm{M}$ CNQX/50 $\mu \mathrm{M}$ D-APV. The cells depolarize under ACSF $+\mathrm{CarBa}$. This depolarization is not reversed under ACSF + CarBa + CNQX/D-APV. Single-cell values in gray, mean \pm SD in black. b Plot of sigma under the same pharmacological conditions. Sigma increases under ACSF $+\mathrm{CarBa}$, but this increase is b

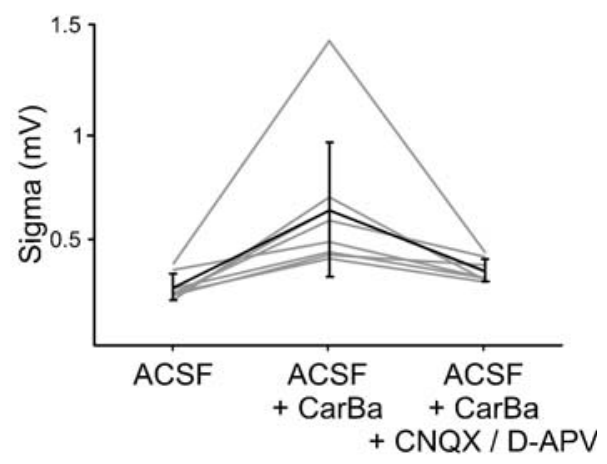

d

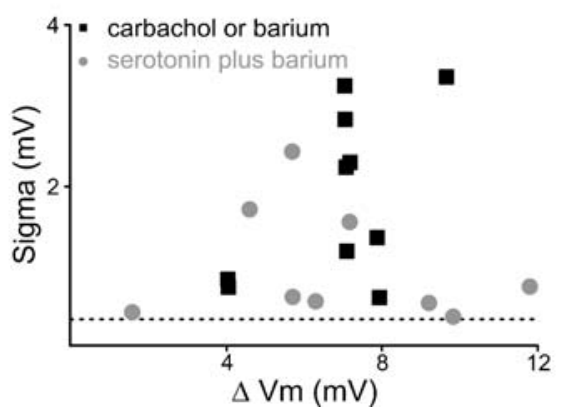

reversed under ACSF $+\mathrm{CarBa}+\mathrm{CNQX} / \mathrm{D}-\mathrm{APV}$. $\mathbf{c}$ Plot of the changes in sigma against the changes in membrane potential in 19 cells. A stronger depolarization of the cells under study is not correlated with an increased synaptic drive of the surrounding network reflected in sigma. d Plot of absolute values of sigma against the changes in membrane potential. The cells analyzed for $\mathbf{c}$ and $\mathbf{d}$ are identical to those in Fig. 4, except for serotonin. Dashed lines show the control level in ACSF 
Fig. 6 Sigma and $T /$ sigma are not correlated with input resistance. a The input resistance was monitored with current injections between -100 and -400 pA. 50 micromoles of barium increases the input resistance, while $20 \mu \mathrm{M}$ of serotonin lower it. A mixture of serotonin and barium results in an intermediate effect. b The plot of changes in sigma against changes in input resistance does not show a correlation. c Also, the plot of $T /$ sigma against changes in input resistance does not show a correlation. The cells analyzed are identical to those in Fig. 4. Dashed lines show the control level in ACSF. Mice P14 (a, left and middle part) and P15 (a, right part) a

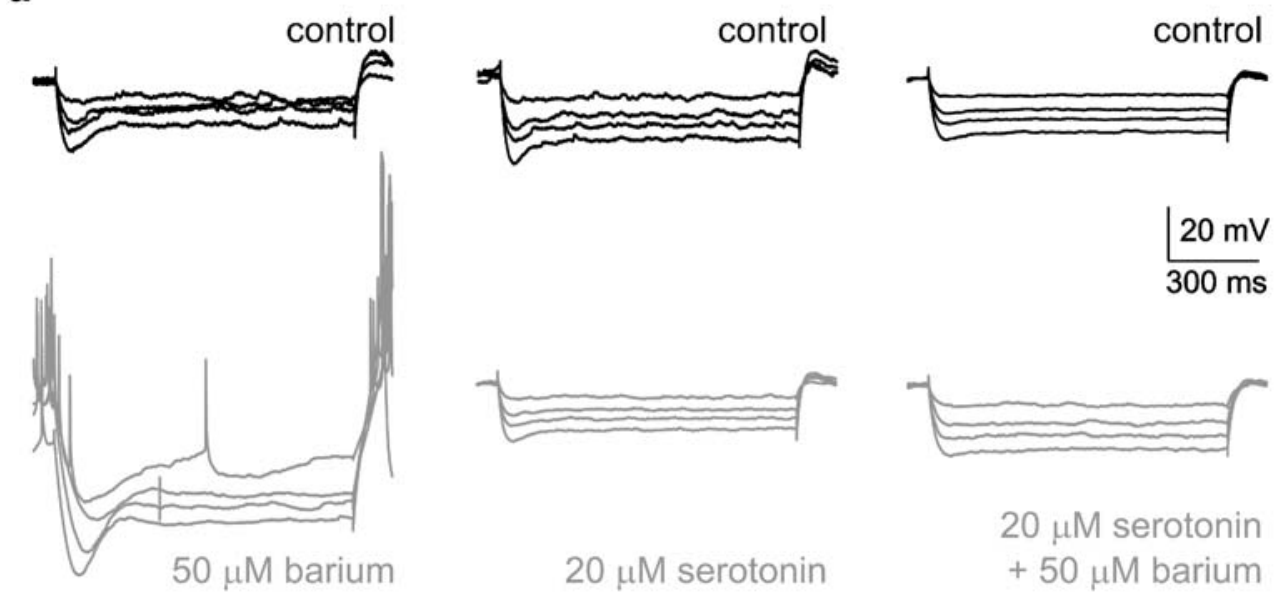

b

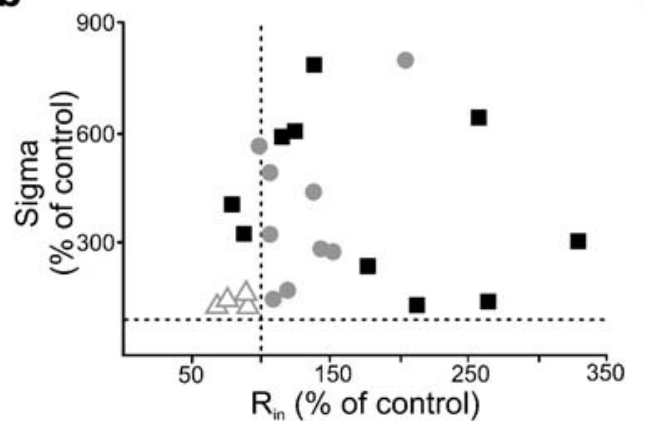

c

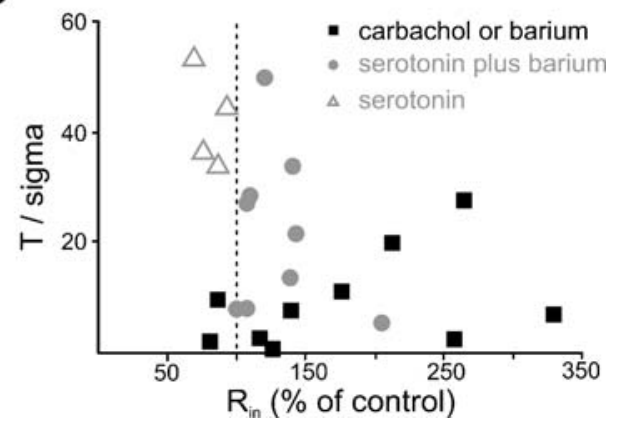

depolarization and ceased to generate action potentials. Activation with increased extracellular potassium and decreased calcium and magnesium concentrations resulted in a sufficient but only transient decrease of $T /$ sigma. Thus, these conditions did not result in INA.

Modulation of cholinergic and serotoninergic conductances establishes stable and reversible increased network activity

Subcortical serotoninergic and cholinergic fibers trigger wakefulness and responsiveness of cortical neurons to sensory stimuli, forming part of the ascending arousal system [37, 48]. We mimicked the cholinergic input using bath application of carbachol, an acetylcholine analog, or barium, a specific blocker of inward rectifier potassium channels [54]. These are downstream targets of the cholinergic action [23,31]. Alternatively or in addition we applied serotonin, which acted in our system via an activation of persistent sodium channels (supplementary Fig. 1). We used the following pharmacological conditions: (a) cholinergic activation, $20 \mu \mathrm{M}$ carbachol, $50 \mu \mathrm{M}$ barium, or $100 \mu \mathrm{M}$ barium; (b) serotonin $20 \mu \mathrm{M}$; and (c) mixed activation, $10 \mu \mathrm{M}$ serotonin plus $20 \mu \mathrm{M}$ barium or $20 \mu \mathrm{M}$ serotonin plus $50 \mu \mathrm{M}$ barium. Data sets for the action of carbachol $(n=2$ cells $), 50 \mu \mathrm{M}$ barium $(n=4$ cells $)$, or $100 \mu \mathrm{M}$ barium $(n=4$ cells) showed comparable steady- state effects on passive membrane properties. Therefore, they were pooled using the term "cholinergic activation" despite the fact that the blocking effect of barium on inwardly rectifier potassium channels might not reflect the full range of acetylcholine effects. We also pooled the values for mixed activation via different concentrations of serotonin and barium.

In all three pharmacological conditions, neurons depolarized, sigma increased, and the effective difference between mean $\mathrm{Vm}$ and spiking threshold was reduced, but the extent of these changes was different for the different pharmacological interventions (Figs. 3 and 4; Table 1). Using cholinergic activation, the cells depolarized by $9.5 \pm$ $6.7 \mathrm{mV}(p<0.01 ; n=10$ cells $)$ and sigma increased to $420.4 \pm$ $207.4 \%$ of control $(p<0.01 ; n=10$; Fig. 3a; Table 1). $T /$ sigma was reduced to $12.0 \pm 12.0 \quad(p<0.01 ; n=10)$. Spiking activity was seen with a median of $0.42 \mathrm{~Hz}$ (range $0-5.0 \mathrm{~Hz} ; n=10$ ). In contrast to barium, carbachol initially hyperpolarized the cells for 2-3 $\mathrm{min}$ before reaching the depolarized steady-state level. In addition, the carbachol effect was the only one that was not fully reversible (not shown). Serotoninergic activation alone resulted in weaker effects. The change of $\mathrm{Vm}$ of $3.3 \pm 2.9 \mathrm{mV}$ was not significant ( $p=0.37 ; n=4$ cells). The change in sigma to $184.4 \pm 32.0 \%$ of control was significant $(p=0.011 ; n=4$ cells; Fig. 3b; Table 1), and $T /$ sigma was decreased to 
a Stimulation intensity $200 \mu \mathrm{A}$
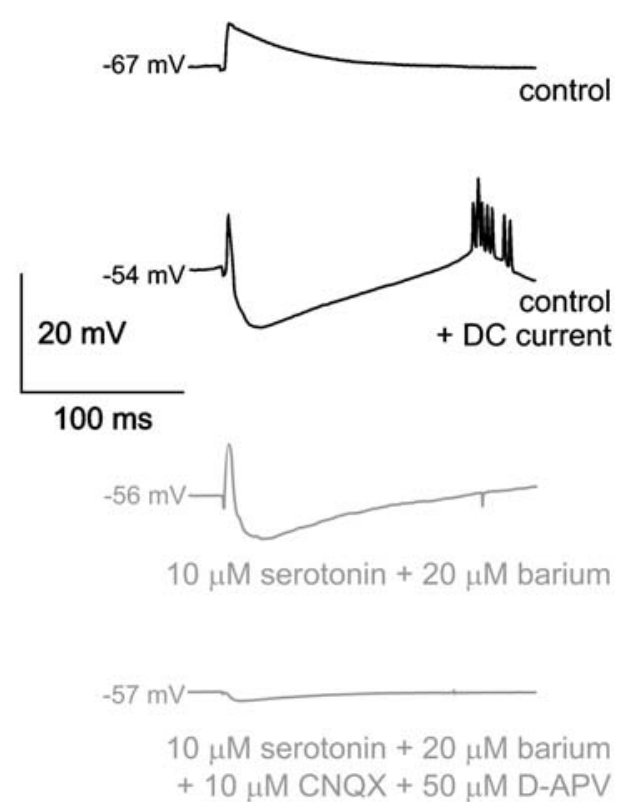

b

\section{Stimulation intensity $300 \mu \mathrm{A}$}

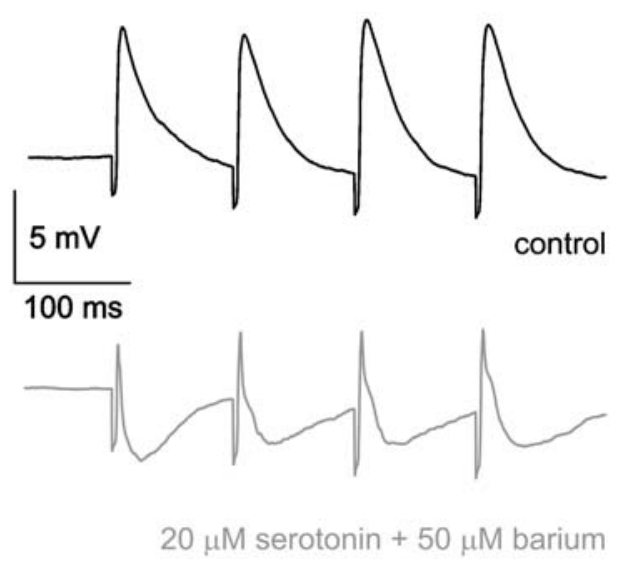

Fig. 7 INA increases the driving force for inhibitory inputs. a Activation of synaptic input by extracellular stimulation in layer 2 (400 $\mu$ s duration, $200 \mu \mathrm{A}$ amplitude, 10 trials averaged; uppermost trace). Under control conditions, an EPSP is evoked. At a depolarized membrane potential due to DC current injection, a diphasic response with an EPSP and an additional inhibitory component is observed (second trace from top). Mixed cholinergic-serotoninergic activation depolarizes the cell and stimulation results in a comparable EPSPIPSP sequence (third trace from top). Additional application of CNQX and D-APV results in the disappearance of all synaptic activity except a tiny monosynaptic inhibitory activity (trace on bottom). b A train of four pulses $(400 \mu$ s duration, $300 \mu \mathrm{A}$ amplitude, $10 \mathrm{~Hz}, 30$ trials

$41.1 \pm 7.7(p<0.01 ; n=4$ cells; Fig. 4). Spiking could not be observed under serotonin. Mixed serotoninergic-cholinergic activation led to comparable effects on membrane potential depolarization and fluctuation in comparison to cholinergic activation alone. Cells depolarized by $10.0 \pm$
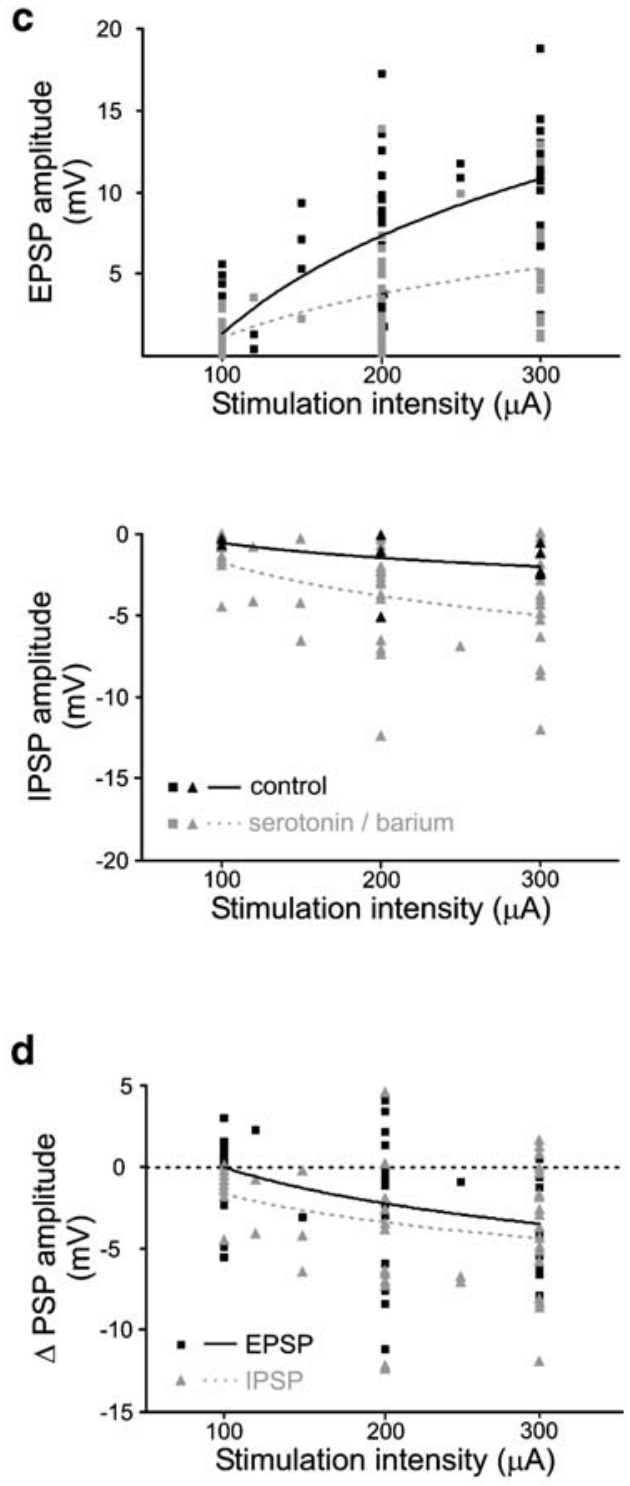

averaged) evokes EPSPs under control conditions (black trace). Under mixed cholinergic-serotoninergic activation, the evoked EPSPs are curtailed by disynaptic IPSPs (gray trace). c EPSP and IPSP amplitudes are plotted as a function of the stimulation intensity. Solid black symbols give the amplitude under control, bordered gray symbols depict the amplitude during mixed cholinergic-serotoninergic activation. Curves are logarithmic fits of the data sets. d Changes in EPSP and IPSP amplitude following the switch to mixed cholinergicserotoninergic activation. EPSP changes are depicted as black rectangles, IPSP changes as triangles. A negative value means a decrease in EPSP size but an increase in the IPSP size. Mice P27 (a), P15 (b)

$5.1 \mathrm{mV}(p<0.01 ; n=9$ cells $)$ and sigma increased to $404.3 \pm$ $221.7 \%$ of control $(p<0.01 ; n=9$; Fig. $3 \mathrm{c}$; Table 1$)$. The effective difference to spiking threshold $T$ /sigma decreased to $22.0 \pm 14.7(p<0.01 ; n=9$; Fig. 4$)$. Spiking activity was seen at $0.1 \mathrm{~Hz}$ (median; range 0 to $3.1 \mathrm{~Hz} ; n=9$ ). 
Fig. 8 INA decreases the critical frequency for dendritic calcium action potentials. The ability of layer 5 pyramidal cells to generate dendritic calcium action potentials was studied with four induced somatic action potentials at different frequencies. a-c Somatic membrane potential (first row, single trials). At the branchpoint of the distal apical dendrite ( $625 \mu \mathrm{m}$ from the soma; see inset) changes in intracellular calcium concentration were imaged as changes in the fluorescence of the high-affinity calcium dye OGB-1 (following rows). Averaged signals from 10 trials, taken from a $100-\mu \mathrm{m}$ segment of the dendrite. Electrophysiology and imaging are not aligned. a Below the so-called critical frequency (here $125 \mathrm{~Hz}$ ), no dendritic calcium transients are visible under control conditions. b Mixed cholinergicserotoninergic activation depolarizes the cell. In addition, the critical frequency is decreased to $77 \mathrm{~Hz}$ and the amplitude of calcium events increases to $263 \%$ of control. $\mathbf{c}$ Repolarization of the somatic membrane potential with DC current injection to the control value changes the amplitude of dendritic calcium events and the critical frequency only marginally. d For the cell shown in a-c, the evoked changes of the calcium concentration in the dendrite are plotted against the frequency of induced somatic action potentials. During INA, calcium transients increase and the critical frequency is lowered. e For 14 cells, the shift in the critical frequency under INA is shown. Mouse P27 (a-d) a electrophysiology soma

$143 \mathrm{~Hz}$

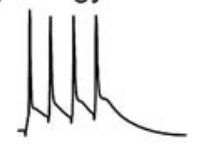

imaging

dendrite

$143 \mathrm{~Hz}$

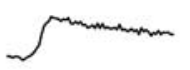

$125 \mathrm{~Hz}$

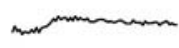

$111 \mathrm{~Hz}$

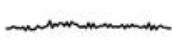

$100 \mathrm{~Hz}$

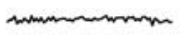

$83 \mathrm{~Hz}$

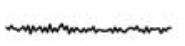

$77 \mathrm{~Hz}$

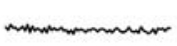

$71 \mathrm{~Hz}$

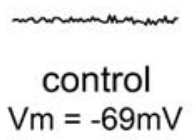

b
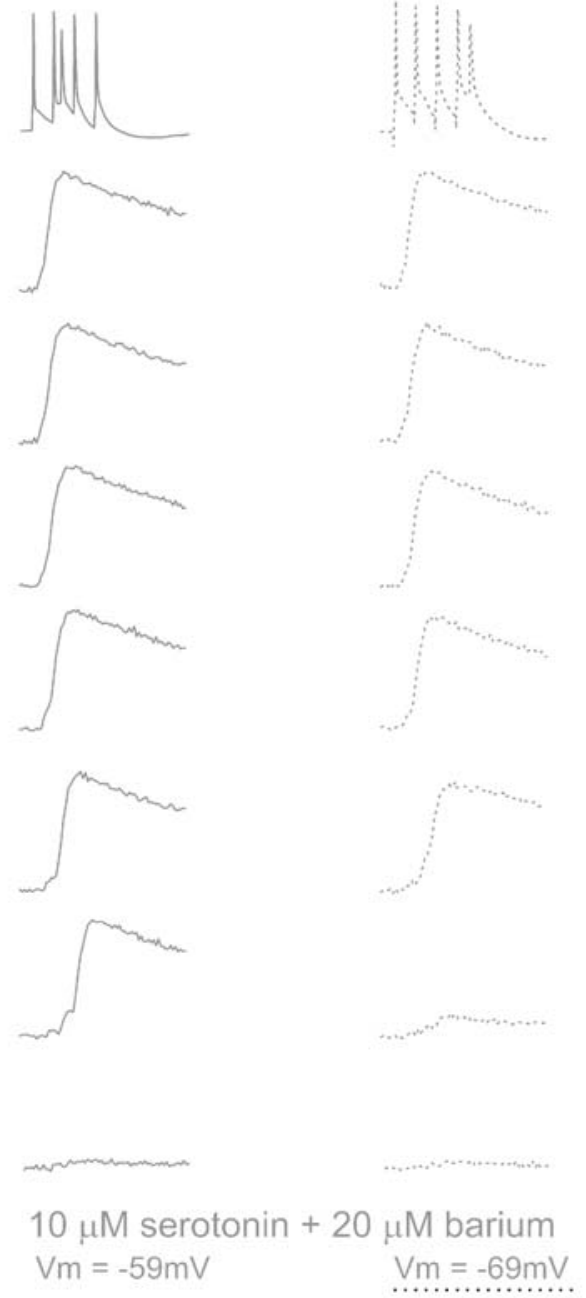
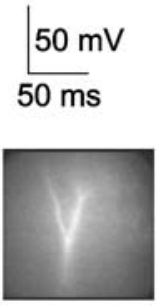

$50 \% \Delta F / F$
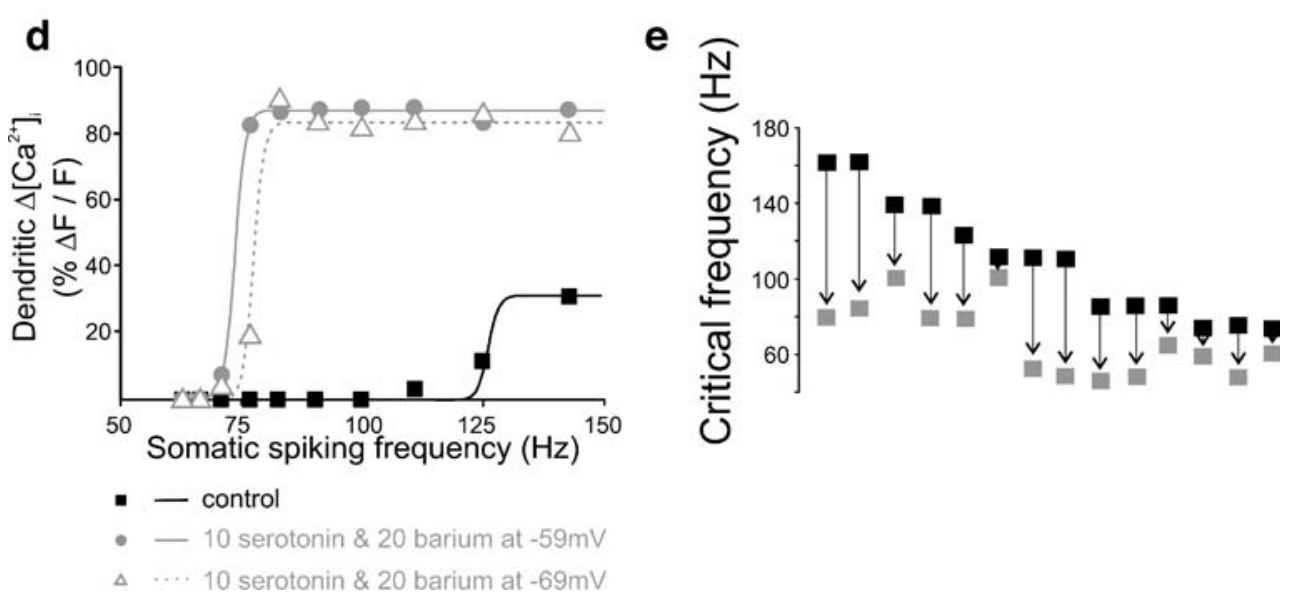

Thus, the strongest depolarizing effects and the largest increase in network synaptic drive were observed with cholinergic or mixed serotoninergic-cholinergic activation, while serotonin alone had minor effects. For cholinergic or mixed serotoninergic-cholinergic activation, T/sigma was in the requested range of values (Fig. 4), and electrophysiological behavior was stable and did not limit recording time. Thus, we refer to these conditions as INA. 
Fig. 9 During INA, the GABAergic veto effect is present. To test if distal GABAergic input is able to suppress dendritic calcium action potentials (veto effect), we simultaneously evoked both signals during mixed cholinergic-serotoninergic activation. Left column, somatic membrane potential (single trials); right column, imaged dendritic calcium changes (averaged from 10 trials, taken from a $100-\mu \mathrm{m}$ segment of the dendrite). a Four somatic action potentials at $111 \mathrm{~Hz}$ evoke a dendritic calcium event that is accompanied by a somatic afterdepolarization with overlying additional spikes. b Distal extracellular stimulation at $300 \mu \mathrm{A}$ evokes an IPSP, which does not show up at all in the calcium signal. c The combination of four somatic spikes at $111 \mathrm{~Hz}$ with a distal extracellular stimulation at $100 \mu \mathrm{A}$ still results in a dendritic calcium event but with a reduced amplitude in comparison to somatic spikes alone. The somatic afterdepolarization is still present. Increasing the extracellular stimulation intensity to 200 and $300 \mu \mathrm{A}$ results in the disappearance of the dendritic calcium signal and the somatic afterdepolarization. Mouse P27 a

\section{$10 \mu \mathrm{M}$ serotonin $+20 \mu \mathrm{M}$ barium}
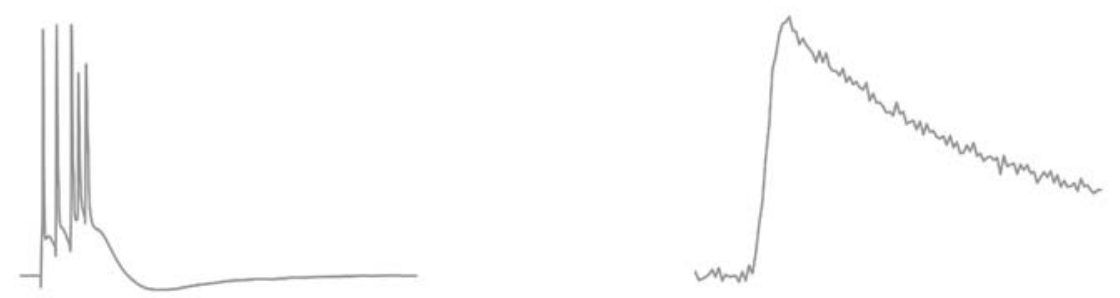

b

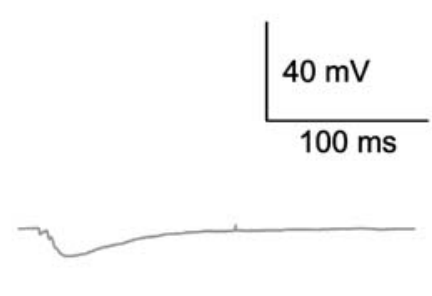

four somatic spikes at $111 \mathrm{~Hz}$

distal extracellular stimulation with $300 \mu \mathrm{A}$

C
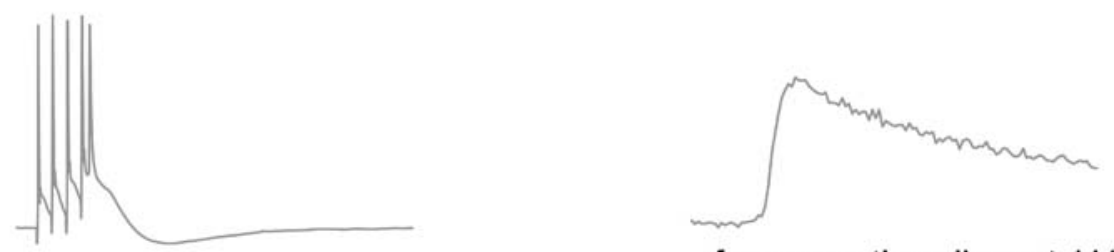

four somatic spikes at $111 \mathrm{~Hz}$ + distal extracellular stimulation with $100 \mu \mathrm{A}$
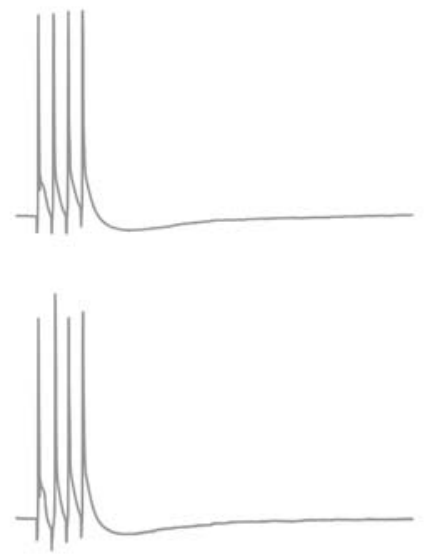

four somatic spikes at $111 \mathrm{~Hz}$ + distal extracellular stimulation with $200 \mu \mathrm{A}$

\section{undrommen-minem \\ four somatic spikes at $111 \mathrm{~Hz}$ \\ + distal extracellular stimulation with $300 \mu \mathrm{A}$}

Depolarization due to modulation of intrinsic conductances is the main factor for increased network activity

Depolarization of the neurons could be caused either by the modulation of intrinsic leak conductances that hyperpolarize the cells under control conditions or by a net excitatory synaptic drive emerging from the surrounding network. To get an estimate for the importance of the synaptic drive for depolarization during INA, we activated the network with $20 \mu \mathrm{M}$ carbachol or $50 \mu \mathrm{M}$ barium and then blocked synaptic conductances with $10 \mu \mathrm{M}$ CNQX and $50 \mu \mathrm{M}$ D-APV. Under these conditions, depolarization had an amplitude of $128.1 \pm 41.4 \%$ of the depolarization seen with carbachol or barium alone (difference not significant, $p=0.19 ; n=8$ cells; Fig. 5a). Sigma under carbachol or barium plus CNQX/D-APV was markedly reduced in comparison to carbachol or barium $(62.0 \pm 17.3 \% ; p<0.01$; $n=8$ cells; Fig. 5 b). That it was still larger in comparison to the control value in ACSF $(133.0 \pm 25.6 \% ; p=0.012)$ might be attributed to inhibitory input or to excitatory neurotransmitters other than glutamate. Next, we plotted the depolarization of a given cell against its sigma, either against the percentage of the control value (Fig. 5c) or against its absolute value (Fig. 5d), and found no 
Table 1 Electrophysiological properties of layer 5 pyramidal cells under different pharmacological conditions

\begin{tabular}{|c|c|c|c|c|c|c|c|c|}
\hline & $\begin{array}{l}\Delta \mathrm{Vm}(\mathrm{mV}) \\
(\text { mean } \pm \mathrm{SD})\end{array}$ & $\begin{array}{l}T(\mathrm{mV}) \\
(\text { mean } \pm \\
\mathrm{SD})\end{array}$ & $\begin{array}{l}\text { sigma }(\mathrm{mV}) \\
\text { (range, } \\
\text { median) }\end{array}$ & $\begin{array}{l}\text { sigma }(\% \text { of } \\
\text { control) (mean } \pm \\
\text { SD) }\end{array}$ & $\begin{array}{l}T / \text { sigma } \\
(\text { mean } \pm \\
\text { SD) }\end{array}$ & $\begin{array}{l}\text { Spiking } \\
\text { frequency }(\mathrm{Hz}) \\
\text { (range, median) }\end{array}$ & $\begin{array}{l}\mathrm{R}_{\text {in }}(\% \text { of } \\
\text { control) (mean } \pm \\
\mathrm{SD})\end{array}$ & $\begin{array}{l}\text { tau }(\% \text { of } \\
\text { control) (mean } \pm \\
\text { SD) }\end{array}$ \\
\hline \multirow[t]{2}{*}{$\begin{array}{l}\text { ACSF } \\
\text { (control) }\end{array}$} & 0 & $25.3 \pm 7.4$ & $\begin{array}{l}0.17-0.92, \\
0.35\end{array}$ & 100 & $71.6 \pm 37.8$ & 0 & 100 & 100 \\
\hline & $n=54$ & $n=54$ & $n=43$ & $n=43$ & $n=43$ & $n=54$ & $n=54$ & $n=54$ \\
\hline \multirow[t]{2}{*}{ LTX } & $2.5 \pm 3.0$ & $29.5 \pm 10.4$ & $\begin{array}{l}0.49-1.86 \\
0.94\end{array}$ & $187 \pm 63.8$ & $\begin{array}{l}35.3 \pm \\
23.6^{*}\end{array}$ & $0-0.12,0$ & $109 \pm 27.7$ & $94 \pm 8.5$ \\
\hline & $n=5$ & $n=5$ & $n=5$ & $n=5$ & $n=5$ & $n=5$ & $n=5$ & $n=5$ \\
\hline \multirow[t]{2}{*}{ PDX } & $3.3 \pm 2.4^{* *}$ & $25.8 \pm 11.1$ & $\begin{array}{l}0.28-0.76 \\
0.345\end{array}$ & $141 \pm 34.1 * *$ & $59.7 \pm 45.2$ & $0-0.05,0$ & $95 \pm 26.8$ & $95 \pm 29.6$ \\
\hline & $n=8$ & $n=5$ & $n=8$ & $n=8$ & $n=5$ & $n=8$ & $n=6$ & $n=8$ \\
\hline \multirow[t]{2}{*}{$5 \mathrm{~K}^{+}$} & $13.3 \pm 5.6^{* *}$ & $\begin{array}{l}17.2 \pm \\
3.3 * *\end{array}$ & $0.73-2.23,0.8$ & $222.8 \pm 94.4^{*}$ & $\begin{array}{l}18.7 \pm \\
7.5 * *\end{array}$ & $0-15.3,0.2$ & $72.3 \pm 38.0^{*}$ & $63.9 \pm 22.9^{* *}$ \\
\hline & $n=12$ & $n=12$ & $n=5$ & $n=5$ & $n=5$ & $n=12$ & $n=12$ & $n=12$ \\
\hline \multirow[t]{2}{*}{$6.25 \mathrm{~K}^{+}$} & $18.4 \pm 11.1^{* *}$ & $\begin{array}{l}15.6 \pm \\
2.7 * *\end{array}$ & $0.5-2.02,1.24$ & $256.6 \pm 71.5^{*}$ & $\begin{array}{l}15.8 \pm \\
8.7 * *\end{array}$ & $0-13.0,1.15$ & $79.3 \pm 28.5^{*}$ & $51.3 \pm 21.4^{* *}$ \\
\hline & $n=8$ & $n=8$ & $n=6$ & $n=6$ & $n=6$ & $n=8$ & $n=8$ & $n=8$ \\
\hline \multirow[t]{2}{*}{ CarBa } & $9.5 \pm 6.7 * *$ & $\begin{array}{l}10.9 \pm \\
7.0^{* *}\end{array}$ & $\begin{array}{l}0.55-3.35 \\
1.16\end{array}$ & $420.4 \pm 207 * *$ & $\begin{array}{l}12.0 \pm \\
12.0^{* *}\end{array}$ & $0-5.0,0.42$ & $174.8 \pm 71.0^{* *}$ & $168.5 \pm 53.8^{* *}$ \\
\hline & $n=10$ & $n=10$ & $n=10$ & $n=10$ & $n=10$ & $n=10$ & $n=10$ & $n=10$ \\
\hline \multirow[t]{2}{*}{ Ser } & $3.3 \pm 2.9$ & $16.1 \pm 2.2 *$ & $\begin{array}{l}0.32-0.46 \\
0.405\end{array}$ & $184.4 \pm 32.0^{*}$ & $\begin{array}{l}41.1 \pm \\
7.7 * *\end{array}$ & $0-0.01,0$ & $77.5 \pm 8.5$ & $91.6 \pm 7.3$ \\
\hline & $n=4$ & $n=4$ & $n=4$ & $n=4$ & $n=4$ & $n=4$ & $n=4$ & $n=4$ \\
\hline \multirow[t]{2}{*}{ SerBa } & $10.0 \pm 5.1 * *$ & $\begin{array}{l}13.8 \pm \\
2.4^{* *}\end{array}$ & $\begin{array}{l}0.34-2.41 \\
0.52\end{array}$ & $404.3 \pm 221^{* *}$ & $\begin{array}{l}22.0 \pm \\
14.7^{* *}\end{array}$ & $0-3.1,0.1$ & $127.2 \pm 32.4^{* *}$ & $139.1 \pm 21.8^{* *}$ \\
\hline & $n=9$ & $n=9$ & $n=9$ & $n=9$ & $n=9$ & $n=9$ & $n=9$ & $n=9$ \\
\hline $\begin{array}{l}\text { Estimated } \\
\text { ranges } \\
\text { in vivo }\end{array}$ & - & $2-30$ & $1.4-12$ & - & $<1-12$ & $0.06-45$ & - & - \\
\hline
\end{tabular}

The parameters input resistance, membrane time constant, and mean spiking rate are not part of the INA definition. We include them to provide a more complete picture of the induced conditions. The in vivo values for $T$ and sigma were given in or had to be estimated from figures in Baranyi et al. [4], Chen and Fetz [10], Crochet and Petersen [11], DeWeese and Zador [15], Lee et al. [29], Margrie et al. [33], Matsumura et al. [34], Rudolph et al. [41], and Steriade et al. [49]. Spiking frequencies were taken from Chen and Fetz [10], Crochet and Petersen [11], DeWeese and Zador [15], Margrie et al. [33], Rudolph et al. [41], Steriade et al. [49], and Woody et al. [57].

$\Delta V m$ change in membrane potential; $T$ difference between mean membrane potential and spiking threshold; sigma SD of the Gaussian-fitted membrane potential distribution; $R_{\text {in }}$ input resistance; tau membrane time constant; ACSF control conditions in standard ACSF; LTX $\alpha$-latrotoxin; $P D X$ pardaxin; $5 K^{+}$mACSF with $5 \mathrm{mM} \mathrm{KCl}, 1.5 \mathrm{CaCl}_{2}, 0.5 \mathrm{mM} \mathrm{MgCl}_{2} ; 6.25 \mathrm{~K}^{+} \mathrm{mACSF}$ with $6.25 \mathrm{mM} \mathrm{KCl}_{1} 1.5 \mathrm{CaCl}_{2}, 0.5 \mathrm{mM} \mathrm{MgCl}_{2}$; CarBa cholinergic activation with carbachol or barium; Ser serotonin; SerBa mixed cholinergic-serotoninergic activation with barium and serotonin

$* 0.01<p \leq 0.05 ; * * p \leq 0.01$

correlation. These findings supported an intrinsic origin of the depolarization, while the synaptic network drive had no relevant effect in this preparation.

To test how changes of passive membrane properties due to cholinergic and serotoninergic activation may influence sigma or $T /$ sigma, we evaluated the changes in input resistance related to the pharmacological intervention. Cholinergic activation resulted in an increase in input resistance to $174.8 \pm 71.0 \%$ of control $(p<0.01 ; n=10$ cells; Fig. 6a left part; Table 1). In contrast, serotoninergic activation did not change input resistance significantly (77.5 $\pm 8.5 \%$ of control; $p=0.12 ; n=4$ cells; Fig. 6 a middle 
part). With a mixed serotoninergic-cholinergic activation, the value for input resistance was between that for purely serotoninergic or cholinergic activation $(127.2 \pm 32.4 \%$ of control, $p<0.01, n=9$ cells; Fig. 6a right part). Membrane time constant was changed accordingly in all conditions (Table 1).

Next, we checked whether changes in input resistance were related to changes in sigma or $T /$ sigma. A plot of both parameters did not give any correlation (Fig. 6b,c). This suggests that network activity reflected by sigma and the ability to generate INA (low $T /$ sigma) did not depend on a net change of input resistance. As a consequence, the resulting depolarization must have been the primary factor that drove the cells and the network.

Increased network activity augments the driving force for inhibitory inputs

Comparable to $\alpha$-latrotoxin and mACSF (Figs. 1d and 2d), we tested how INA changes synaptic integration using extracellular stimulation (Fig. 7). EPSPs were markedly reduced in amplitude ( $70 \%$ of control) and duration under cholinergic or serotoninergic-cholinergic activation (stimulation intensity $100-300 \mu \mathrm{A} ; 59$ data points obtained in 17 cells; Fig. 7a-d). These changes were accompanied by the appearance of an inhibitory disynaptic activity in 15 out of 17 cells (Fig. 7a, second trace from bottom). In 2 out of 17 cells, the disynaptic component was excitatory (not shown). The inhibitory component was nearly exclusively due to disynaptic activation because only a minor part was present under $10 \mu \mathrm{M}$ CNQX and $50 \mu \mathrm{M}$ D-APV (Fig. 7a, trace on bottom). The inhibitory disynaptic response could be mimicked if the cells were depolarized under control conditions by DC current injection to values obtained with serotonin plus barium (Fig. 7a, second trace from top). This suggests a role of the modified driving forces for chloride, potassium, and cationic conductances of $\mathrm{GABA}_{\mathrm{A}}, \mathrm{GABA}_{\mathrm{B}}$, and AMPA receptors, respectively, under INA.

Increased network activity boosts dendritic calcium events

To study dendritic activity in layer 5 pyramidal cell under INA, we prepared parasagittal slices from P27 to P30 mice ( $n=14$ cells). Comparing the properties of INA following serotoninergic-cholinergic activation, differences between cells from the P14-P15 and the P27-P30 age groups are not significant. In the P27-P30 age group, sigma has a range of $0.37-0.85 \mathrm{mV}$ with a median of $0.54 \mathrm{mV}$. $T$ is $14.2 \pm$ $5.6 \mathrm{mV}(13.8 \pm 2.4 \mathrm{mV}$ in P14-P15 cells; $p=0.78)$, while $T /$ sigma is $27.7 \pm 11.8(22.0 \pm 14.7$ in P14-P15 cells; $p=0.12$ ). Dendritic calcium events are best evoked due to a combined somatic and dendritic activation, suggesting that they need coincident input arriving at different cortical layers to occur [27]. However, somatic action potentials alone can also induce dendritic calcium activity if they surpass a so-called critical frequency [7, 25]. Four somatic action potentials were induced at different frequencies, and the presence of a consecutive dendritic event was seen as an afterdepolarization in the somatic trace $(n=14$ cells, not shown). In six cells, this was combined with a detection of the distal dendritic calcium signal using epifluorescence imaging (Fig. 8). We found a critical frequency of $120.8 \pm$ $11.0 \mathrm{~Hz}$ under control (Fig. 8a), which was reduced to $59.8 \pm 5.0 \mathrm{~Hz}$ in serotoninergic-cholinergic INA (Fig. $8 \mathrm{~b}$, d,e), reflecting $57.0 \pm 4.1 \%$ of control ( $n=14$ cells). In seven cells under serotoninergic-cholinergic activation, DC current was injected to hyperpolarize the somatic membrane back to the value recorded under control conditions (Fig. 8c,d). Then, the critical frequency was unchanged and did not increase to the values found under control (compare Berger et al. [7] and Larkum et al. [25]).

Under increased network activity the GABAergic veto effect is still intact

A prominent feature of dendritic calcium events is their strong control via distal GABAergic inputs (veto effect $[27,39])$. Therefore, we investigated the effects of distal dendritic stimulation on a dendritic calcium event evoked under serotoninergic-cholinergic INA with four somatic action potentials (Fig. 9). Somatic activity beyond the critical frequency evoked a dendritic calcium transient (Fig. 9a, dendritic imaging data in the right part), which was accompanied by a strong somatic afterdepolarization and overlying action potentials (Fig. 9a, somatic membrane potential in the left part). Distal extracellular stimulation alone evoked a hyperpolarization-dominated postsynaptic response, which was, of course, not correlated to a calcium signal (Fig. 9b). In eight cells, concomitant and increasing extracellular stimulation abolished the somatic afterdepolarization, as well as the calcium event (Fig. 9c). Thus, also under conditions of a facilitated initiation of dendritic calcium events, distal inhibitory input is powerful enough to stop this activity.

\section{Discussion}

Definition of increased network activity

Acute slice preparations are the ideal system for electrophysiological studies of single cells and optical imaging in the cerebral cortex, as they provide major methodological advantages. All layers can be targeted. A high degree of visibility allows the recording from selected cell types and cellular compartments. Direct access enables local extracel- 
lular drug application and absence of movement provides stable recordings. The physiological relevance of in vitro measurements, however, is limited due to altered integrative properties of the system. Here, we show that INA can be evoked in a stable and fully reversible manner in acute brain slices mimicking subcortical input. This enables a sophisticated level of investigation of neuronal integration at subcellular resolution, which is not feasible in the awake animal.

The first criterion of our definition of INA considers the probability of $\mathrm{Vm}$ to reach the spiking threshold. All studies using intracellular recordings in awake animals indicate low $T /$ sigma values in a range between 1 and 12 (estimations from Baranyi et al. [4], Chen and Fetz [10], Crochet and Petersen [11], DeWeese and Zador [15], Lee et al. [29], Margrie et al. [33], Matsumura et al. [34], Rudolph et al. [41], and Steriade et al. [49]). In contrast, standard slice preparations are characterized by an extreme increase of $T /$ sigma (to about 100, Destexhe et al. [14]; to 71.6 , this study). The underlying mechanism is a consistently lowered sigma in the slice situation $(0.18 \mathrm{mV}$, Paré et al. [38]; $0.35 \mathrm{mV}$, this study) in comparison to the nonanesthetized animal (sigma of about $2 \mathrm{mV}$ [14]), and a much more hyperpolarized $\mathrm{Vm}$ in vitro ( $T$ of about $20 \mathrm{mV}$, Destexhe et al. [14]; $25.3 \mathrm{mV}$, this study). An apparent advantage of the $T /$ sigma parameter is the possibility of distinguishing intense subthreshold integration from only minute subthreshold activity (Fig. 4). If Vm values are not Gaussian-distributed, e.g., in cases of a highly coincident synaptic drive (auditory cortex [15]), the probability of action potentials might transiently be higher than indicated by $T /$ sigma.

Our two criteria for INA (see "Results" section) consider (a) the low $T /$ sigma values in vivo and (b) the fact that induced network activity should always be sustainable. One can argue that the action potential rate should also be included in the definition of INA. However, the literature is quite contradictory with respect to the spiking frequency in awake animals. Recordings of cortical cells reveal large differences in spiking frequencies (range 0.06-45 Hz [10, $11,15,33,41,49,57])$ that seem not to be due to different recording techniques [56]. Because of this disagreement, we do not include spiking rates in the definition of INA. In contrast, the $T /$ sigma paradigm even provides a possible explanation for differing rates of spiking in vivo. At the low $T$ levels observed in vivo, slight changes of sigma are sufficient to cause quite heterogeneous spiking frequencies.

Depolarization via modulated intrinsic conductances is the key mechanism for increased network activity

Large $T /$ sigma values in the untreated cortical slice normally prevent action potential output, while the pre- served connectivity in this preparation in general is sufficient to generate network activity [32, 47, this study]. As active membrane properties are intact in vitro, two possible factors remain that can be responsible for the enormous $T /$ sigma and the electrophysiological quiescence in the slice: lack of synaptic drive and alteration of passive membrane properties. During INA, synaptic drive mediated by ionotropic conductances for sure contributes to the reduction of $T /$ sigma, as sigma is increased in all cells under study and is in the range found in nonanesthetized animals (mean $1.16 \mathrm{mV}$ for cholinergic and $0.52 \mathrm{mV}$ for serotoninergic-cholinergic activation, compared to about $2 \mathrm{mV}$ in vivo [14]). However, it was not clear whether the increase of sigma and the reduction of $T$ were correlated phenomena. Blocking excitatory synaptic transmission under INA, we find that the depolarization remains while sigma approaches the control values seen in ACSF. This means that the modulation of intrinsic conductances provides a sufficient degree of depolarization on the basis of which suprathreshold integration of synaptic input can take place. Taken together, the depolarization during INA seems to be due to the modulation of intrinsic conductances and does not depend on a net excitatory synaptic drive.

The input resistance is a passive membrane property that could determine the impact of synaptic input on Vm and sigma. On the one hand, depolarizing synaptic activity is able to lower the input resistance of cortical neurons in vivo $[13,14]$. On the other hand, depolarizating events can also reliably be associated with an increase in input resistance if intrinsic conductances come into play that counteract the shunting effect of synaptic input [56]. In our study, INA is accompanied by an increased input resistance, but this increase is correlated neither with sigma nor with $T /$ sigma. Therefore, an increase of input resistance is not a prerequisite for the induction of INA. This finding is supported by our experiments with a changed ionic composition of the extracellular solution (mACSF). In this case, low $T /$ sigma values and an elevated spiking rate are associated with a markedly decreased input resistance. Thus, low $T /$ sigma values can be obtained under conditions that include either an increase or a decrease of input resistance. The possible independence of network activity from input resistance is further corroborated by the study of Steriade and coworkers [49], which shows that comparable spiking rates can be observed at very different levels of input resistance. During wakefulness, the input resistance in cortical cells is almost doubled in comparison to the depolarizing phase of slow wave sleep, while the spiking rate is even lower. As we have discussed above, INA depends on the depolarization of neurons, which is mainly based on the tuning of intrinsic leak conductances and only to a minor degree, if at all, on a modification of input resistance. 
Cholinergic modulation of the cortical function is complex [31]. m1 Muscarinic acetylcholine receptors inhibit G protein-coupled inwardly rectifying potassium channels (GIRK channels [22]) while $\mathrm{m} 2$ receptors activate them. Accordingly, muscarinic activation of the cortex can lead either to excitatory phenomena like gamma oscillations [8] or dampening effects, e.g., on synaptic integration in pyramidal cell dendrites [17, 44]. Using carbachol, Vm depolarization and an increase in input resistance are consistent with the blocking effect of acetylcholine on resting potassium conductances [23]. With barium, we specifically select the effect on inwardly rectifying potassium channels [54]. Barium has comparable effects to acetylcholine, and their effects are not additive [23]. In this study, carbachol and barium have comparable effects, and cells are pooled.

Serotonin has been shown to have several effects on cortical cells via ionotropic and metabotropic receptors. It activates GIRK channels in layer 5 pyramidal cells of the somatosensory cortex via 5-HT1A receptors [54]. However, this effect is delayed during development [45] and, therefore, may be of less importance at the age range studied here. 5-HT2 receptors have been shown to activate the persistent sodium current in spinal cord motoneurons [18]. The persistent sodium conductance is an important factor for the excitability of layer 5 pyramidal cells in the somatosensory cortex [3]. Using voltage-clamp recordings in layer 5 pyramidal cells, we find that serotonin indeed activates the persistent sodium current (supplementary Fig. 1). This effect can explain the depolarization under serotonin seen in the present study.

In vitro, long-range afferents of both kinds, ionotropic and subcortical neuromodulatory ones, are severed due to the slice preparation. Pure activation of the presynaptic release machinery using $\alpha$-latrotoxin or pardaxin is ineffective in providing INA, indicating that the lack of ionotropic input is not the main reason for the silent state in slice preparations. Proper subthreshold activity is not sufficient to push $\mathrm{Vm}$ to threshold as long as cells stay locked in an unphysiological hyperpolarization. Our findings suggest that the in vitro slice preparation mainly lacks subcortical neuromodulatory input providing depolarization. Restoring this input is sufficient for the generation of INA.

Synaptic and somatodendritic integration in layer 5 pyramidal cells under increased network activity

The apical dendrite of layer 5 pyramidal cells of the somatosensory cortex is actively taking part in the integration of synaptic input. Generation of calcium action potentials in the distal dendrite is regulated by synaptic and intrinsic conductances. Inhibitory synaptic drive via GABA receptors impairs the initiation of dendritic calcium events (veto effect [39]). Dendritic calcium spikes may result from the interaction of sensory and associative signals [27]. In addition, resting conductances like Ih [5, 7] and GIRK [55] separate somatic and dendritic initiation zones electrotonically. The effectiveness of boosting and dampening conductances is dramatically influenced by changes in the actual membrane potential and in the passive membrane properties. Unfortunately, the knowledge about the interactions in the dendrite primarily derives from recordings in untreated slices where passive membrane properties are altered. In vivo, dendrites of layer $2 / 3$ and layer 5 pyramidal cells are able to generate so-called complex action potentials $[19,26,53,58]$, which seem to be the correlate of calcium events observed in vitro. There is, however, not a one-to-one relationship between dendritic calcium event and somatic action potential burst [19]. Such observations cannot be addressed in detail due to the limitations of in vivo experiments. Therefore, it is highly desirable to study dendritic phenomena under well-manageable conditions with INA.

Here, we show that distal extracellular stimulation under INA is dominated by disynaptic inhibition, which dramatically curtails the evoked EPSP. This strengthened inhibition is primarily due to an increased driving force for chloride, while the driving force for the cationic glutamatergic conductance is diminished. At lower stimulation intensity $(100 \mu \mathrm{A})$, the size of the EPSPs is almost the same under INA and control (Fig. 7d). Thus, it seems unlikely that there is an additional direct effect of INA on the release probability of excitatory synapses. The depolarized conditions in vivo may therefore result in a comparably pronounced inhibitory action. The overall control of inhibitory synaptic conductances over excitatory ones is expected to be strengthened (see Schiller et al. [42]), as well as thalamocortical feedforward inhibition [52] and, in particular, the dendritic veto effect [27]. Therefore, we studied the changes in dendritic excitability under INA. Compared to standard in vitro conditions, we find a strong decrease in the frequency of somatic action potentials critical for the induction of dendritic calcium action potentials and an increase of the amplitude of the dendritic calcium response. In contrast to the effect of GABAergic synaptic inhibition, this facilitation is not compensated by somatic hyperpolarizing DC current injection. Thus, it does not seem to be a depolarization of the dendritic initiation zone that decreases the critical frequency but a modulation of the input resistance and membrane time constant. Alternatively, an insufficient space-clamp of the dendritic initiation zone may cause the failure to prevent dendritic calcium action potentials (but see Berger et al. [7]). Our data suggest that blocking dendritic GIRK channels with carbachol or barium prolongs the membrane time constant of dendrites and thereby facilitates dendritic electrogenesis. 
Activation of persistent sodium currents via serotonin may ease action potential backpropagation and further favor calcium spikes $[43,51]$. In spite of the facilitated dendritic excitability, boosted disynaptic inhibition is strong enough to prevent calcium spikes. These experiments show that, in the somatosensory cortex, the veto effect first described in vitro [27] is present under INA levels.

Acknowledgements We thank Drs. Alain Destexhe, Michele Giugliano, Serge Korogod, Matthew Larkum, and Hans-R. Lüscher for useful discussions and comments on earlier versions of the manuscript. This work was supported by the Swiss National Foundation (Grant 3100-107529/1) and the Novartis Foundation for MedicalBiological Research.

Disclosures There are no conflicts of interest.

\section{References}

1. Abeles M (1982) Local cortical circuits - an electrophysiological study. Springer, Berlin Heidelberg New York

2. Agmon A, Connors BW (1991) Thalamocortical responses of mouse somatosensory (barrel) cortex in vitro. Neuroscience 41:365-379

3. Aracri P, Colombo E, Mantegazza M, Scalmani P, Curia G, Avanzini G, Franceschetti S (2006) Layer-specific properties of the persistent sodium current in sensorimotor cortex. J Neurophysiol 95:3460-3468

4. Baranyi A, Szente MB, Woody CD (1993) Electrophysiological characterization of different types of neurons recorded in vivo in the motor cortex of the cat. II. Membrane parameters, action potentials, current-induced voltage responses and electrotonic structures. J Neurophysiol 69:1865-1879

5. Berger T, Larkum ME, Lüscher HR (2001) High $I_{h}$ channel density in the distal apical dendrite of layer $\mathrm{V}$ pyramidal cells increases bidirectional attenuation of EPSPs. J Neurophysiol 85:855-868

6. Berger T, Lüscher HR, Giugliano M (2006) Transient rhythmic network activity in the somatosensory cortex evoked by distributed input in vitro. Neuroscience 140:1401-1413

7. Berger T, Senn W, Lüscher HR (2003) Hyperpolarizationactivated current $I_{h}$ disconnects somatic and dendritic spike initiation zones in layer $\mathrm{V}$ pyramidal neurons. J Neurophysiol 90:2428-2437

8. Buhl EH, Tamas G, Fisahn A (1998) Cholinergic activation and tonic excitation induce persistent gamma oscillations in mouse somatosensory cortex in vitro. J Physiol 513:117-126

9. Capogna M, Gähwiler BH, Thompson SM (1996) Calciumindependent actions of alpha-latrotoxin on spontaneous and evoked synaptic transmission in the hippocampus. J Neurophysiol 76:3149-3158

10. Chen D, Fetz EE (2005) Characteristic membrane potential trajectories in primate sensorimotor cortex neurons recorded in vivo. J Neurophysiol 94:2713-2725

11. Crochet S, Petersen CC (2006) Correlating whisker behavior with membrane potential in barrel cortex of awake mice. Nat Neurosci 9:608-610

12. Descarries L, Gisiger V, Steriade M (1997) Diffuse transmission by acetylcholine in the CNS. Prog Neurobiol 53:603-625

13. Destexhe A, Pare D (1999) Impact of network activity on the integrative properties of neocortical pyramidal neurons in vivo. $\mathrm{J}$ Neurophysiol 81:1531-1547
14. Destexhe A, Rudolph M, Pare D (2003) The high-conductance state of neocortical neurons in vivo. Nat Rev Neurosci 4:739-751

15. DeWeese MR, Zador AM (2006) Non-Gaussian membrane potential dynamics imply sparse, synchronous activity in auditory cortex. J Neurosci 26:12206-12218

16. Grasso A, Alema S, Rufini S, Senni MI (1980) Black widow spider toxin-induced calcium fluxes and transmitter release in a neurosecretory cell line. Nature 283:774-776

17. Gulledge AT, Stuart GJ (2005) Cholinergic inhibition of neocortical pyramidal neurons. J Neurosci 25:10308-10320

18. Harvey PJ, Li X, Li Y, Bennett DJ (2006) 5-HT2 receptor activation facilitates a persistent sodium current and repetitive firing in spinal motoneurons of rats with and without chronic spinal cord injury. J Neurophysiol 96:1158-1170

19. Helmchen F, Svoboda K, Denk W, Tank DW (1999) In vivo dendritic calcium dynamics in deep-layer cortical pyramidal neurons. Nat Neurosci 2:989-996

20. Henkel AW, Sankaranarayanan S (1999) Mechanisms of alphalatrotoxin action. Cell Tissue Res 296:229-233

21. Henze DA, McMahon DB, Harris KM, Barrionuevo G (2002) Giant miniature EPSCs at the hippocampal mossy fiber to CA3 pyramidal cell synapse are monoquantal. J Neurophysiol 87:15-29

22. Hill JJ, Peralta EG (2001) Inhibition of a Gi-activated potassium channel (GIRK1/4) by the Gq-coupled $\mathrm{m} 1$ muscarinic acetylcholine receptor. J Biol Chem 276:5505-5510

23. Krnjevic K, Pumain R, Renaud L (1971a) Effects of $\mathrm{Ba}^{2+}$ and tetraethylammonium on cortical neurones. J Physiol 215:223-245

24. Krnjevic K, Pumain R, Renaud L (1971b) The mechanism of excitation by acetylcholine in the cerebral cortex. J Physiol 215:247-268

25. Larkum ME, Kaiser KM, Sakmann B (1999a) Calcium electrogenesis in distal apical dendrites of layer 5 pyramidal cells at a critical frequency of back-propagating action potentials. Proc Natl Acad Sci USA 96:14600-14604

26. Larkum ME, Zhu JJ (2002) Signaling of layer 1 and whiskerevoked $\mathrm{Ca}^{2+}$ and $\mathrm{Na}^{+}$action potentials in distal and terminal dendrites of rat neocortical pyramidal neurons in vitro and in vivo. J Neurosci 22:6991-7005

27. Larkum ME, Zhu JJ, Sakmann B (1999b) A new cellular mechanism for coupling inputs arriving at different cortical layers. Nature 398:338-341

28. Lazarovici P, Lelkes PI (1992) Pardaxin induces exocytosis in bovine adrenal medullary chromaffin cells independent of calcium. J Pharmacol Exp Ther 263:1317-1326

29. Lee AK, Manns ID, Sakmann B, Brecht M (2006) Whole-cell recordings in freely moving rats. Neuron 51:399-407

30. London M, Häusser M (2005) Dendritic computation. Annu Rev Neurosci 28:503-532

31. Lucas-Meunier E, Fossier P, Baux G, Amar M (2003) Cholinergic modulation of the cortical neuronal network. Pflugers Arch 446:17-29

32. Maclean JN, Watson BO, Aaron GB, Yuste R (2005) Internal dynamics determine the cortical response to thalamic stimulation. Neuron 48:811-823

33. Margrie TW, Brecht M, Sakmann B (2002) In vivo, lowresistance, whole-cell recordings from neurons in the anaesthetized and awake mammalian brain. Pflugers Arch 444:491-498

34. Matsumura M, Cope T, Fetz EE (1988) Sustained excitatory synaptic input to motor cortex neurons in awake animals revealed by intracellular recording of membrane potentials. Exp Brain Res 70:463-469

35. McCormick DA (1989) Cholinergic and noradrenergic modulation of thalamocortical processing. Trends Neurosci 12:215-221

36. McCormick DA, Prince DA (1986) Mechanisms of action of acetylcholine in the guinea-pig cerebral cortex in vitro. J Physiol 375:169-194 
37. Miller DB, O'Callaghan JP (2006) The pharmacology of wakefulness. Metabolism 55(Suppl 2):S13-S19

38. Paré D, Shink E, Gaudreau H, Destexhe A, Lang EJ (1998) Impact of spontaneous synaptic activity on the resting properties of cat neocortical pyramidal neurons in vivo. J Neurophysiol 79:1450-1460

39. Perez-Garci E, Gassmann M, Bettler B, Larkum ME (2006) The GABAB1b isoform mediates long-lasting inhibition of dendritic $\mathrm{Ca}^{2+}$ spikes in layer 5 somatosensory pyramidal neurons. Neuron 50:603-616

40. Petrenko AG (1993) Alpha-Latrotoxin receptor. Implications in nerve terminal function. FEBS Lett 325:81-85

41. Rudolph M, Pospischil M, Timofeev I, Destexhe A (2007) Inhibition determines membrane potential dynamics and controls action potential generation in awake and sleeping cat cortex. $\mathrm{J}$ Neurosci 27:5280-5290

42. Schiller J, Schiller Y, Stuart G, Sakmann B (1997) Calcium action potentials restricted to distal apical dendrites of rat neocortical pyramidal neurons. J Physiol 505:605-616

43. Schwindt PC, Crill WE (1995) Amplification of synaptic current by persistent sodium conductance in apical dendrite of neocortical neurons. J Neurophysiol 74:2220-2224

44. Seeger T, Alzheimer C (2001) Muscarinic activation of inwardly rectifying $\mathrm{K}^{+}$conductance reduces EPSPs in rat hippocampal CA1 pyramidal cells. J Physiol 535:383-396

45. Sickmann T, Alzheimer C (2003) Short-term desensitization of G-protein-activated, inwardly rectifying $\mathrm{K}^{+}$(GIRK) currents in pyramidal neurons of rat neocortex. J Neurophysiol 90: 2494-2503

46. Sidiropoulou K, Pissadaki EK, Poirazi P (2006) Inside the brain of a neuron. EMBO Rep 7:886-892

47. Silberberg G, Wu C, Markram H (2004) Synaptic dynamics control the timing of neuronal excitation in the activated neocortical microcircuit. J Physiol 556:19-27
48. Steriade M, McCarley R (2005) Brain control of wakefulness and sleeping. Plenum, New York

49. Steriade M, Timofeev I, Grenier F (2001) Natural waking and sleep states: a view from inside neocortical neurons. J Neurophysiol 85:1969-1985

50. Stuart GJ, Sakmann B (1994) Active propagation of somatic action potentials into neocortical pyramidal cell dendrites. Nature 367:69-72

51. Stuart GJ, Sakmann B (1995) Amplification of EPSPs by axosomatic sodium channels in neocortical pyramidal neurons. Neuron 15:1065-1076

52. Sun QQ, Huguenard JR, Prince DA (2006) Barrel cortex microcircuits: thalamocortical feedforward inhibition in spiny stellate cells is mediated by a small number of fast-spiking interneurons. $\mathrm{J}$ Neurosci 26:1219-1230

53. Svoboda K, Denk W, Kleinfeld D, Tank DW (1997) In vivo dendritic calcium dynamics in neocortical pyramidal neurons. Nature 385:161-165

54. Takigawa T, Alzheimer C (1999) G protein-activated inwardly rectifying $\mathrm{K}^{+}(\mathrm{GIRK})$ currents in dendrites of rat neocortical pyramidal cells. J Physiol 517:385-390

55. Takigawa T, Alzheimer C (2003) Interplay between activation of GIRK current and deactivation of $\mathrm{I}_{\mathrm{h}}$ modifies temporal integration of excitatory input in CA1 pyramidal cells. J Neurophysiol 89:2238-2244

56. Waters J, Helmchen F (2006) Background synaptic activity is sparse in neocortex. J Neurosci 26:8267-8277

57. Woody CD, Swartz BE, Gruen E (1978) Effects of acetylcholine and cyclic GMP on input resistance of cortical neurons in awake cats. Brain Res 158:373-395

58. Zhu Y, Zhu JJ (2004) Rapid arrival and integration of ascending sensory information in layer 1 nonpyramidal neurons and tuft dendrites of layer 5 pyramidal neurons of the neocortex. J Neurosci 24:1272-1279 